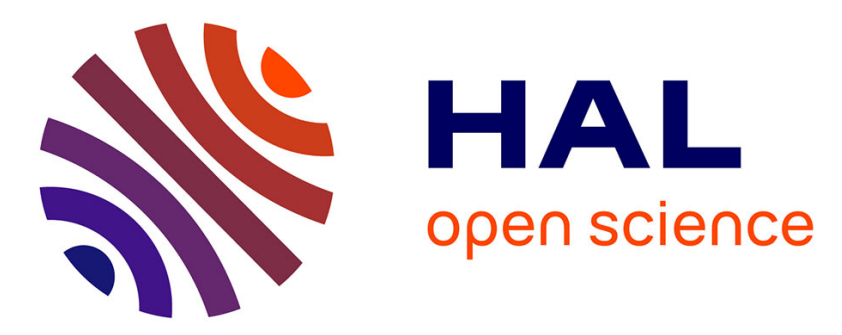

\title{
Capillary condensation and adsorption of binary mixtures
}

Benno Weinberger, Farida Darkrim-Lamari, Dominique Levesque

\section{To cite this version:}

Benno Weinberger, Farida Darkrim-Lamari, Dominique Levesque. Capillary condensation and adsorption of binary mixtures. Journal of Chemical Physics, 2006, 124 (23), pp.234712. 10.1063/1.2205848 . hal-00278736

\section{HAL Id: hal-00278736 https://hal.science/hal-00278736}

Submitted on 13 May 2008

HAL is a multi-disciplinary open access archive for the deposit and dissemination of scientific research documents, whether they are published or not. The documents may come from teaching and research institutions in France or abroad, or from public or private research centers.
L'archive ouverte pluridisciplinaire HAL, est destinée au dépôt et à la diffusion de documents scientifiques de niveau recherche, publiés ou non, émanant des établissements d'enseignement et de recherche français ou étrangers, des laboratoires publics ou privés. 


\title{
Capillary condensation and adsorption of binary mixtures
}

\author{
B. Weinberger and F. Darkrim-Lamari \\ LIMHP UPR CNRS 1311 Université Paris XIII 93430 Villetaneuse, France* \\ D. Levesque \\ Laboratoire de Physique Théorique UMR CNRS 8627 \\ Université Paris Sud Bâtiment 210, 91405 Orsay, France ${ }^{\dagger}$
}

\begin{abstract}
The adsorption of equimolar binary mixtures of hydrogen-carbon dioxide, hydrogen-methane and methane-carbon dioxide in porous material models is determined by Grand Canonical Monte Carlo simulations. The material models have an adsorbent surface similar to that of nanofibers with a herringbone structure. Our main result, which is relevant for hydrogen purification and carbon dioxide capture, is that the adsorption selectivities calculated for the mixtures can differ significantly from those deduced from simulations of the adsorption of pure gases, in particular when one of the adsorbed gases presents a capillary condensation induced by confinement within the pore network. A comparison of our data is also made with theoretical models used in the literature for predicting the properties of the mixture adsorption.
\end{abstract}

PACS numbers:

*Author to whom correspondance should be addressed.

Electronic address: farida.darkrim@limhp.univ-paris13.fr.

${ }^{\dagger}$ Electronic address: dominique.levesque@th.u-psud.fr 


\section{INTRODUCTION}

The main application of the adsorption in porous materials is the separation of gaseous mixtures into their different components [1] and, in future, the capture of greenhouse gas emission [2]. The efficiency of these purification processes depends on the interactions and sizes of the component molecules which determine the ability of each molecule type to be adsorbed in the pore network of materials. The carbonaceous porous materials are an adsorbent class often used in the gas separation. Among these materials, the carbon nanofibers (CNF) or graphite nanofibers (GNF) have been actively studied in particular as a possible material for the hydrogen gas storage [3-9].

Numerous theoretical works on the gas adsorption in carbonaceous materials have been published in the literature [10-22]. They studied the properties of material models where the adsorbent surface was constituted by graphite basal planes or the external and internal surfaces of single or multi-walled carbon nanotubes. Most of these works concerned the adsorption of pure gases, but some have been devoted to that of mixtures [23-25]. In the present work, by using Grand Canonical Monte Carlo (GCMC) simulations, we study the adsorption of gas mixtures on a model of GNF with a herringbone structure. The simulations allow to compute the selectivity, a quantity characterizing the purification capacity of a porous material. In addition to the theoretical determination of adsorption properties of GNF, our aim is to contribute to the improvement of purification processes by showing that a physical interpretation of the selectivities of binary mixtures can be made from the density profiles computed for the mixture components and pure gases inside a typical pore of a porous material.

The simulations have been realized for equimolar mixtures of $\mathrm{H}_{2}$ and $\mathrm{CO}_{2}, \mathrm{H}_{2}$ and $\mathrm{CH}_{4}$, and $\mathrm{CH}_{4}$ and $\mathrm{CO}_{2}$. This relative concentration has been chosen because it is to the order of magnitude of that present in the industrial purification processes. It seems adequate for obtaining a good estimate of the selectivities for mixtures where the relative concentrations have similar values, i.e $30-50 \%$.

Section II is devoted to the description of the GNF model and that of molecular and atomic potentials used in the simulations. In section III, the simulation results are presented, discussed, and compared to those of theoretical models used to predict the properties of the pure gas and mixture adsorption. In the conclusion, we stress on the importance of the 
$\mathrm{CO}_{2}$ capillary condensation in the studied adsorption processes when they take place at a temperature and pressure close to $300 \mathrm{~K}$ and 5.0 MPa.

\section{MODEL AND INTERACTIONS}

In GCMC simulations, the adsorption processes of physisorption type result from van der Waals interactions between the adsorbed fluids and adsorbent materials. They are described at a microscopic scale and the adsorption properties of a specific porous material are obtained from those of nanopores considered as being mainly present in the material pore network.

In this work, a porous material constituted by GNF is studied. The GNF are supposed to have a herringbone structure made up by graphene sheets tilted with respect to the fiber axis [26]. The GNF adsorbent surfaces are formed by the rows of carbon atoms located at the external edges of the graphene sheets. These carbon atoms have pending bonds which can be functionalized by chemical groups. Inside the material model, the nanopores are supposed to be slits delimited by stacks of graphite planes, separated from another by a distance of $0.34 \mathrm{~nm}$, where the external carbon atoms are functionalized with $H$ atoms [27]. Then, the adsorbing walls of the pores are constituded by $C H$ groups. The superficial density of these adsorbing sites is 12.0 per $\mathrm{nm}^{2}$. It is smaller than that of adsorbing sites ( $C$ atoms) of graphite basal planes equal to 38.0 per $\mathrm{nm}^{2}$. But, the lower superficial density of adsorbing $\mathrm{CH}$ groups is compensated by their stronger van der Waals interaction with adsorbed gases compared to that of $C$ atoms located in graphite planes (cf. Table I below).

In the simulation volume or simulation cell, the two stacks defining the slit, disposed parallel to the oy axis, are separated by a distance $d$ between their $C H$ groups. The stacks are periodically replicated in the $y$ and $z$ directions and the slit, formed by two stacks and the space between these stacks, replicated in the $x$ direction. The stacks are tilted with respect to the $z$ axis, supposed parallel to the fiber axis, by 30 degrees. The extent of graphite planes in the $x$ direction corresponds to 3 hexagons of carbon atoms and is equal to $D \simeq 1.1$ $\mathrm{nm}$ including the $\mathrm{CH}$ group size on the edges. It has been chosen in taking into account the fast decreasing of the van der Waals interactions between gas molecules and carbon atoms located inside the stacks. A larger width of the stacks in the $x$ direction would not contribute

significantly to increase the gas molecule adsorption on the GNF external surfaces. As a consequence of the chosen values of $D$, the specific surface of the adsorbent model, defined 
as the surface of the adsorbent per unit of adsorbent mass is equal $1032 \mathrm{~m}^{2} / \mathrm{gr}$. With this geometry, the adsorption in the slit pore should correspond to a quasi maximal value of the ratios : mass and excess mass of adsorbed gas on adsorbent mass, ratios which, muliplied by a factor of 100, are defined in the literature as weigth per cent and excess weigth per cent of a porous material [28-30]. The slit widths $d$, considered in the simulations, are, respectively, equal to $1.0 \mathrm{~nm}, 2.5 \mathrm{~nm}$ and $5.0 \mathrm{~nm}$. Each stack is formed by 16 graphite planes and the total number of $C$ atoms present in the cells is equal to 3264 and that of $C H$ groups equal to 1088 .

Fig. 1 presents a three-dimensional view of the pore model and a molecule typical configuration of an adsorbed $\mathrm{H}_{2}-\mathrm{CO}_{2}$ mixture in equilibrium with a bulk equimolar $\mathrm{H}_{2}-\mathrm{CO}_{2}$ mixture at a temperature of $293 \mathrm{~K}$ and total pressure of $10.0 \mathrm{MPa}$.

The intermolecular van der Waals interactions of gases and those between gas molecules and adsorbent are represented by Lennard-Jones (LJ) potentials. For $\mathrm{H}_{2}$ and $\mathrm{CH}_{4}$ molecules and $C H$ groups, the united-atom approximation [31] is used and an only LJ potential, located at the center of mass, represents the van der Waals interactions. For $\mathrm{CO}_{2}$, the van der Waals interactions are described by 3 LJ potentials located at the positions of the $C$ and $O$ atoms $[32,33]$. In addition to these LJ interactions, $\mathrm{H}_{2}$ and $\mathrm{CO}_{2}$ molecules have a linear electric quadrupole, described by a neutral distribution of 3 charges located, respectively, for $\mathrm{H}_{2}$ at the positions of protons (charge $q$ ) and center of mass (charge $-2 q$ ) and for $\mathrm{CO}_{2}$ at those of the $O$ atoms (charge $q$ ) and $C$ atom (charge $-2 q$ ).

The LJ potentials $v_{L J}(r)=4 \epsilon\left[(\sigma / r)^{12}-(\sigma / r)^{6}\right]$ are defined by the parameters $\epsilon$ and $\sigma$. The values of these parameters, those of the charges associated to the electric quadrupoles of $\mathrm{H}_{2}$ and $\mathrm{CO}_{2}$ and the positions $l$ of the charges $q$, relative to the center of mass along the molecule axis, are given in Table I. The parameters of LJ potentials for the $C$ atoms and CH groups [31] present in the GNF are also given in Table I. The parameters of the LJ cross interactions between atoms of different molecule species and between these atoms and GNF are obtained from the Berthelot's rules summarized by the relations $\epsilon_{\alpha \beta}=\sqrt{\epsilon_{\alpha}} \epsilon_{\beta}$ and $\sigma_{\alpha \beta}=\left(\sigma_{\alpha}+\sigma_{\beta}\right) / 2$. where $\epsilon_{\alpha}, \epsilon_{\beta}, \sigma_{\alpha}$ and $\sigma_{\beta}$ denote the LJ parameters of gas molecules and LJ parameters associated to GNF atoms and chemical groups. 


\section{RESULTS AND DISCUSSSIONS}

In a GCMC simulation, the composition of a mixture adsorbed in a porous medium is obtained by determining the equilibrium state between the adsorbed mixture and a bulk mixture with a given composition, pressure and temperature. Such a computation is realized by performing a GCMC simulation in a simulation cell, filled with an adsorbent sample, at a temperature and chemical potentials of mixture components equal to those existing in the bulk mixture.

At room temperature and pressures below 10.0 MPa, considered in this work, the species chemical potentials $\mu_{i}^{b}$ ( $i$ index denotes $\mathrm{H}_{2}, \mathrm{CO}_{2}$ or $\mathrm{CH}_{4}$ molecule) in a bulk mixture at fixed temperature, pression and composition can be reasonably estimated from the approximation of perfect mixtures [1]. However, we have determined the values of $\mu_{i}^{b}$ by GCMC simulations performed in an empty simulation cell. The values of $\mu_{i}^{b}$ are modified until the wanted total pressure $P_{T}$ and composition of the bulk mixture are obtained. The total pressure of mixtures and the partial pressures $P_{i}$ of each species having a density $d_{B}^{i}$ are computed by using the virial theorem :

$P_{T}=k T \sum_{i} d_{B}^{i}+\frac{1}{3 V}<\sum_{i} \sum_{k} \mathbf{R}_{k}^{i} \cdot \mathbf{F}_{k}^{i}>+\frac{<\sum_{i} \sum_{k} Q_{k}^{i}>}{3 V}$.

$\mathbf{R}_{k}^{i}$ is the position of the center of mass of the molecule $k$ of species $i$ and $\mathbf{F}_{k}^{i}$ the total force acting on this molecule. $Q_{k}^{i}$ is the contribution to the pressure of the molecular electrical quadrupole which is proportional to the quadrupolar energy [34]. $<$.. > denotes a GC average. The partial pressures $P_{i}$ of the species $i$ correspond to the contributions labelled with a index $i$ in the sums $\sum_{i}$ of Eq. 1 .

The adsorption properties of the GNF pore model, described above, have been computed for pure gases and mixtures from GCMC runs of $12 \times 10^{6}$ Monte-Carlo elementary moves performed after preliminary runs of $8 \times 10^{6} \mathrm{MC}$ moves which allowed to reach the equilibrium state of the adsorbed pure gases or mixtures. The simulation results are presented in Table II for the pure gases and in Table III for the mixtures with pore widths $d$ equal to $1.0 \mathrm{~nm}$ and $2.5 \mathrm{~nm}$. The statistical errors on the amount of adsorbed molecules and density profile are estimated equal to $2-3 \%$ and $3-5 \%$ respectively.

At same temperature and pressure, for pure $\mathrm{H}_{2}, \mathrm{CO}_{2}$ and $\mathrm{CH}_{4}$ the total amounts of adsorbed gases $m_{a}^{i}$, expressed in mole per gram of adsorbent, differ markedly. These dif- 
ferences can be quantitatively assessed by computing a selectivity ratio or separation factor $S_{p}^{i j}$ defined by $S_{p}^{i j}=m_{a}^{i} / m_{a}^{j}$. For a pore width $d=1.0 \mathrm{~nm}$ and pressures from 0 to $5.0 \mathrm{MPa}$, $S_{p}^{C O_{2}, H_{2}}$ varies between 29 and $6, S_{p}^{C O_{2}, C_{4}}$ between 3 and 1.3 and $S_{p}^{C H_{4}, H_{2}}$ between 10 and 4. When $d$ is equal to $2.5 \mathrm{~nm}$, these variations are smaller : between 7 and 5 for $S_{p}^{C O_{2}, H_{2}}$, between 2.9 and 1.5 for $S_{p}^{C O_{2}, \mathrm{CH}_{4}}$ and between 4 and 2.7 for $S_{p}^{C H_{4}, H_{2}}$. In addition, when $d$ changes, the variations of ratios $S_{p}^{i j}$ are different when the pressure increases. Since for the slits of different widths, the pore model keeps an identical adsorption surface, the behaviors of $S_{p}^{i j}$ must be attributed to the change in the local average density $\rho^{i}(x)$ (density profile) inside the pore when $d$ is modified.

The typical density profiles of pure gases at pressures of 0.5 and $5.0 \mathrm{MPa}$ are given in Fig. 2 for $d$ equal to $1.0 \mathrm{~nm}$ and Fig. 3 for $d$ equal to $2.5 \mathrm{~nm}$. The main characteristics of the profiles are the height and width of the peaks located near the adsorbent surfaces which depend on the interaction strength between adsorbed molecules and adsorbent. Clearly the height of peaks indicates that $\mathrm{CO}_{2}$ is more strongly adsorbed than $\mathrm{H}_{2}$, and also $\mathrm{CH}_{4}$, an indication confirming the values of $m_{a}^{i}$ in Table II.

For the pore width $d=1.0 \mathrm{~nm}$ and $P_{T}$ varying from 0.05 to $5.0 \mathrm{MPa}$, the adsorption of $\mathrm{H}_{2}$ increases quasi linearly. The adsorptions of $\mathrm{CO}_{2}$ and $\mathrm{CH}_{4}$, increase fastly between 0.05 and 1.0 MPa, but, above 1.0 MPa, more slowly and seem to go towards an asymptotic maximal value. They correspond to adsorption isotherms of type $\mathrm{I}[1,35]$. The saturation of the adsorption for these two gases results from intermolecular excluded volume effects appearing in particular near the adsorption surface when the local density $\rho^{i}(x)$ becomes large. The variations of $m_{a}^{i}$ explain, for the slit width $d=1.0 \mathrm{~nm}$, the qualitative variations of $S_{p}^{j, i}$. In particular for $S_{p}^{C O_{2}, H_{2}}$ and $S_{p}^{C O_{2}, C_{4}}$, the occurence of a marked maximum at 0.5 $\mathrm{MPa}$ results from the fast increase followed by a slow increase for $P_{T}>1.0 \mathrm{MPa}$ of $\mathrm{CO}_{2}$ and $\mathrm{CH}_{4}$ adsorptions compared to the linear increase of $\mathrm{H}_{2}$ adsorption in the domain of pressures $P_{T}<5.0 \mathrm{MPa}$.

The density profiles, plotted in Fig. 3 for a slit width $d=2.5 \mathrm{~nm}$, show that the central part of the slit is filled by a gas having the density of the bulk phase, excepted for $\mathrm{CO}_{2}$ at 5.0 MPa. The peak widths of $\rho^{i}(x)$ are equal to $\simeq 0.3-0.45 \mathrm{~nm}$ and indicate that the adsorbed molecules are localized near the slit walls in the range of the van der Waals interactions between gas molecules and GNF (cf. Table I). The increase of $m_{a}^{H_{2}}$ for increasing pressures is linear and that of $m_{a}^{C H_{4}}$ also similar to that obtained when $d=1.0 \mathrm{~nm}$. But $m_{a}^{C O_{2}}$ 
increases steadily with $P_{T}$ as consequence of the filling of the central part of the slit by a dense gas which, at $5.0 \mathrm{MPa}$, has a density almost equal to that of $\mathrm{CO}_{2}$ liquid phase in equilibrium with the gaseous phase at $293 \mathrm{~K}$, equal to $17.61 \mathrm{mmol} / \mathrm{cm}^{3}$. The isotherm adsorption of $\mathrm{CO}_{2}$ is of type II $[1,35,36]$ and the strong increase of $m_{a}^{C O_{2}}$ for $P_{T}>3.0 \mathrm{MPa}$ leads to a capillary condensation at $P_{T}=5.0 \mathrm{MPa}$, reminding that, at $293 \mathrm{~K}$, the liquid-gas transition in the bulk fluid takes place at 5.709 MPa. Obviously, the quantitative variations of $S_{p}^{i, j}$ correspond to those of $m_{a}^{i}$. Since the increase of $m_{a}^{H_{2}}$ and $m_{a}^{C H_{4}}$ with pressure are qualitatively similar to that found when the slit width is equal to $1.0 \mathrm{~nm}, S_{p}^{C H_{4}, H_{2}}$ presents a maximum at $P_{T} \simeq 0.25 \mathrm{MPa}$. But, due to the fast increase of $m_{a}^{C O_{2}}$ for $P_{T}>1.0 \mathrm{MPa}$, $S_{p}^{C O_{2}, H_{2}}$ and $S_{p}^{C O_{4}, \mathrm{CH}_{4}}$ increase on all the considered domain of pressures.

From the total amount of adsorbed gases $m_{a}^{i}$ inside a porous material, it is possible to define the excess adsorption $m_{e}^{i}$ by substracting to $m_{a}^{i}$ the contribution associated to the filling of the pore network by the gases at their bulk density, this latter contribution remaining present even if the gas-adsorbent attractive interaction was very weak. $m_{e}^{i}$ is equal to

$m_{e}^{i}=m_{a}^{i}-v_{p} d_{B}^{i} / M_{a}=m_{a}^{i}-m_{B}^{i}$

where $v_{p}$ is the volume of pore network accessible to the adsorbed gas, $d_{B}^{i}$ the density of the bulk gas in mole per volume unit and $M_{a}$ the adsorbent mass. $v_{p}$ can be experimentaly determined by the helium displacement method [37] and, in the numerical simulations, by the procedure described in [38].

The excess adsorptions $m_{e}^{i}$ for pure gases $\mathrm{H}_{2}, \mathrm{CO}_{4}$ and $\mathrm{CH}_{4}$ are given in Table II. They show that the values of $m_{B}^{i}$ always represent a sizeable part of total amounts of adsorbed gases, but as it is seen from Fig. 4 the selectivities $S_{e}^{i, j}=m_{e}^{i} / m_{e}^{j}$ computed from the excess adsorption keep a qualitative behavior similar to those computed with the total adsorption although the values of $S_{e}^{i, j}=m_{e}^{i} / m_{e}^{j}$ are larger than those of $S_{p}^{i, j}$. $S_{e}^{i, j}$ gives a better estimate of the adsorption and selectivity properties of adsorbent surfaces since, excepted when a capillary condensation takes place, $m_{e}^{i}$ corresponds to the gas amount in excess with respect to bulk phase present in the peaks of $\rho^{i}(x)$ or adsorbed layers located near the slit walls.

The GCMC simulations for binary equimolar mixtures have been performed at $293 \mathrm{~K}$ for total pressures $P_{T}$ between 0.1 and 10.0 MPa. The differences between the adsorption of 
pure gases and mixtures can be appreciated by comparing the results obtained at identical temperatures for mixtures and pure phases. To be significant this comparison must be performed for states where the partial pressures and chemical potentials of components are equal to those existing in their pure phases. So, by using Table II and III and Figs. 2, 3 and 5 to 8 , it is seen that for the $\mathrm{CO}_{2}-\mathrm{H}_{2}$ and $\mathrm{CH}_{4}-\mathrm{H}_{2}$ mixtures the amount of adsorbed $H_{2}$ is generally less than it would be expected from the adsorption of the pure gases.

For instance in the the slit $d=1.0$, for $\mathrm{CO}_{2}-H_{2}$ mixture at $P_{T}=1.0 \mathrm{MPa}$ and $P_{H 2}=0.5$ $\mathrm{MPa}, m_{a}^{H_{2}}$ is equal to $0.09 \mathrm{mmol} / \mathrm{gr}$ and equal to $0.166 \mathrm{mmol} / \mathrm{gr}$ for pure $H_{2}$ at $0.5 \mathrm{MPa}$. This decrease of $m_{a}^{H_{2}}$ is more marked in the same mixture at $P_{T}=10.0 \mathrm{MPa}$ and $P_{H 2}=5.7$ MPa. The variation of $m_{a}^{C O_{2}}$ between the pure gas and mixture is weak and of the order of few percent. Similar variations of $m_{a}^{H_{2}}$ and $m_{a}^{C H_{4}}$, quantitatively smaller, are found between pure $\mathrm{H}_{2}$ or pure $\mathrm{CH}_{4}$ and $\mathrm{CH}_{4}-\mathrm{H}_{2}$ mixture. For the $\mathrm{CH}_{4}-\mathrm{CO}_{2}$ mixture, both $\mathrm{m}_{a}^{\mathrm{CH}_{4}}$ and $m_{a}^{C O_{2}}$ present important variations between the adsorptions of mixture and pure gases.

When $d=2.5$, at $P_{T}=1.0 \mathrm{MPa}$ for the mixtures and $P_{T} \simeq 0.5 \mathrm{MPa}$ for the pure gases, the central part of the slit is filled by the bulk mixtures or gases. In spite of the strong localization of adsorbed molecules on adsorbent surface, the superficial density of adsorbed molecules stays low and no excluded volume effect between molecules precludes each mixture component to be adsorbed independently, so that for $\mathrm{CO}_{2}-\mathrm{H}_{2}$ mixture, $m_{a}^{\mathrm{H}_{2}}$ and $m_{a}^{\mathrm{CO}_{2}}$ are equal to 0.3 and $1.84 \mathrm{mmol} / \mathrm{gr}$ and for pure gases to 0.32 and $1.82 \mathrm{mmol} / \mathrm{gr}$. Similar results are obtained for the other mixtures and are in full agreement with the quasi identity of the density profiles in mixtures and pure gases (cf. Fig. 3 and 6).

When the pressure increases this agreement between the adsorptions and density profiles of pure gase and mixtures disappears. At $P_{T}=10.0 \mathrm{MPa}, \rho^{H_{2}}(x)$ differs in $\mathrm{CO}_{2}-\mathrm{H}_{2}$ and $\mathrm{CH}_{4}-\mathrm{H}_{2}$ mixtures, and these two profiles differ from that found for the pure gas at 5.0 MPa. The $m_{a}^{H_{2}}$ values also differ and are respectively 1.26 and $2.42 \mathrm{mmol} / \mathrm{gr}$ for the $\mathrm{CO}_{2}-\mathrm{H}_{2}$ and $\mathrm{CH}_{4}-\mathrm{H}_{2}$ mixtures and $2.99 \mathrm{mmol} / \mathrm{gr}$ for the pure gas. At $P_{T}=10.0 \mathrm{MPa}, \rho^{\mathrm{CH}_{4}}(x)$ in $\mathrm{CH}_{4}$ - $\mathrm{CO}_{2}$ mixture differs strongly from $\mathrm{CH}_{4}$ density profile in pure gas at 5.0 MPa, since the large $\mathrm{CH}_{4}-\mathrm{CO}_{2}$ van der Waals interactions leads to the filling of the slit central part by a dense $\mathrm{CH}_{4}-\mathrm{CO}_{2}$ mixture (capillary condensation), with relative composition 35 - $65 \%$. As in pure $\mathrm{CO}_{2}$, the capillary condensation is also presents in $\mathrm{CO}_{2}-\mathrm{H}_{2}$ mixture. Only $\rho^{\mathrm{CH}_{4}}(x)$ in the $\mathrm{CH}_{4}-\mathrm{H}_{2}$ mixture stays almost idenditical to the density profile in pure gas, the $\mathrm{H}_{2}$ adsorption $\left(m_{a}^{H_{2}}=2.4 \mathrm{mmol} / \mathrm{gr}\right)$ being smaller than that of $\mathrm{CH}_{4}\left(m_{a}^{C H_{4}}=7.3 \mathrm{mmol} / \mathrm{gr}\right)$. 
Similarly to the case of pure gases, the quantities $m_{e}^{i}$ can be defined in the mixtures by using Eq. 2 where $d_{B}^{i}$ is the gas density in the bulk mixture. They are plotted in Fig. 9 and 10 for the two considered witdhs of slits and $P_{T}<10.0 \mathrm{MPa}$. For $d=1.0 \mathrm{~nm}$ the excess adsorption isotherms of $\mathrm{CO}_{2}$ are of type $\mathrm{I}$ in $\mathrm{CO}_{2}-\mathrm{H}_{2}$ and $\mathrm{CO}_{2}-\mathrm{CH}_{4}$ mixtures, that of $\mathrm{CH}_{4}$ is also of type $\mathrm{I}$ in $\mathrm{CH}_{4}-\mathrm{H}_{2}$ mixture. The isotherms of $\mathrm{H}_{2}$ differ strongly of the type I in $\mathrm{CO}_{2}-\mathrm{H}_{2}$ and $\mathrm{CH}_{4}-\mathrm{H}_{2}$ mixtures, because when $P_{T}$ increases, $m_{e}^{H_{2}}$ goes to zero and negative values as a consequence of the fact that $m_{B}^{H_{2}}$ becomes larger than $m_{a}^{H_{2}}$ (cf. $H_{2}$ density profiles in Fig. 7). When $d=2.5$, the two isotherms of $\mathrm{CO}_{2}$ in $\mathrm{CO}_{2}-\mathrm{H}_{2}$ and $\mathrm{CO}_{2}$ - $\mathrm{CH}_{4}$ mixtures are similar to type II isotherms. $\mathrm{CH}_{4}$ isotherm in $\mathrm{CH}_{4}-\mathrm{H}_{2}$ mixture does not reach saturation in the considered domain of $P_{T}$. $H_{2}$ isotherm in $\mathrm{CH}_{4}-\mathrm{H}_{2}$ mixture and $\mathrm{CH}_{4}$ isotherm in $\mathrm{CO}_{2}-\mathrm{CH}_{4}$ have a shape similar to that of the isotherm of type I. In $\mathrm{CO}_{2}$ - $H_{2}, m_{e}^{H_{2}}$ goes to zero with increasing pressures as it is expected from the density profile plotted in Fig. 8.

It is important to mention that the existence of capillary condensation in $\mathrm{CO}_{2}$ pure gas at $P_{T}=5.0 \mathrm{MPa}$ and $\mathrm{CO}_{2}-H_{2}$ mixture at $P_{T}=10.0 \mathrm{MPa}$ is dependent on slit width. This condensation disappears for instance when $d=5.0 \mathrm{~nm}$. As it is seen in Fig. 11, the central part of slit is always occupied by a pure gas or mixture of density and composition equal to that of bulk pure phase or mixture. However, the density profile $H_{2}$ in the mixture differs strongly from that found for the pure gas and stays smaller than $d_{B}^{H_{2}}$.

From the previous discussion of GCMC adsorption results, it appears that the selectivities computed for mixture can present important differences with those calculated from adsorption data for pure gases. A good agreement is obtained only when the mixture components can be adsorded quasi independently, such conditions are realized in the slit $d=1.0 \mathrm{~nm}$ at very low pressures $\simeq 0.1 \mathrm{MPa}$ and slit $d=2.5 \mathrm{~nm}$ for pressures $<0.5 \mathrm{MPa}$. For $P_{T}>1.0$ $\mathrm{MPa}, S_{p}^{i, j}$ and $S_{m}^{i, j}$ generally disagree in particular for the slit $d=1.0 \mathrm{~nm}$ where the excluded volume effects play a major role (cf. Table II and III). The simulation results show that the characterics of adsorption process differ qualitatively with the pore size. The determination of the adsorption properties at a macroscopic scale clearly depends on an estimate of pore size distribution of adsorbing materials.

The interpretation of simulation results by theoretical models can be attempted by using, 
for instance, the Langmuir approach [1, 39] and the associated excess adsorption isotherm $m_{e}^{i}=m_{\max }^{i} \frac{B P_{T}}{1+B P_{T}}$.

The simulation data can be reasonably fitted by the Langmuir isotherm as it is shown in Fig. 12. However the fit is meaningful only when the parameters $m_{\max }^{i}$ and $B$ have values which are physically acceptable. The parameter $m_{\max }^{i}$ in the Langmuir approach corresponds to the maximal density of molecules per unit of adsorbent mass present in the first layer adsorbed on the adsorbent surface. This density is generally estimated to be of the order of magnitude of that of adsorbing sites on the adsorbent surface. In our GNF model, the adsorbing sites are $C H$ groups which have a superficial density of 12.0 per $\mathrm{nm}^{2}$ giving a value of $m_{\max }^{i} \simeq 12.5$ $\mathrm{mmol} / \mathrm{gr}$. The parameter $B$ can be written $C_{a}(T) \exp \left(-E_{a} / k T\right)$. $E_{a}$ is an energy associated to the adsorption of one molecule on the adsorbent surface. The parameter $C_{a}(T)$, depends on temperature and takes into account the other characteristics of the molecular adsorption [1]. The typical values of $E_{a}$, estimated from the minimum of the LJ interactions between molecules and adsorbent are contained between $-100 \mathrm{~K}$ and $-40 \mathrm{~K}$. These estimates give at room temperature $\exp \left(-E_{a} / k T\right) \simeq 1.1-1.4$. Clearly independent values of $m_{\max }^{i}$ and $B$ cannot be obtained when the fitted values of $B$ are such as $B P_{T}<<1$ in the considered range of pressures. When $B P_{T}<<1$, the Langmuir isotherm is similar to the Henry's law isotherm since $m_{e}^{i}$ becomes proportional to $P_{T}$.

The previous remarks lead to conclude that significant values of $m_{\max }^{i}$ and $B$ are obtained from the fit of $\mathrm{CO}_{2}$ and $\mathrm{CH}_{4}$ isotherms for $d=1.0 \mathrm{~nm}$ and that of $\mathrm{CH}_{4}$ isotherm for $d=2.5$. For these 3 isotherms the values of $m_{\max }^{i}$ are, respectively, equal to 10.1, 7.1 and 10.4 and those of $B$ equal to 1.6, 0.6 and 0.2 when $P_{T}$ is expressed in MPa. The values of $m_{\max }^{i}$ are in a reasonable agreement with the estimate made from the superficial density of $C H$ groups.

The fit of the linear isotherms of $H_{2}$ for $d=1$ and $2.5 \mathrm{~nm}$ gives obviously $B P_{T}<<1$., but the products $m_{\max }^{i} B$ have almost identical values 0.19 and 0.21 as it is expected when the adsorption isotherms depend only on the Henry's law constant. The isotherm of $\mathrm{CO}_{2}$ at $d=2.5 \mathrm{~nm}$ is also quasi linear, but the fit cannot be considered as physically significant since the increase of $m_{i}^{e}$ for $P_{T}>3.0 \mathrm{MPa}$ is due to the capillary condensation which is not described by the Langmuir theoretical approach.

The Langmuir isotherm for the component $i$ of a mixture with $n$ components is given by $m_{e}^{i}=m_{\max }^{i} \frac{B_{i} P_{i}}{1+\sum_{j=1, n} B_{j} P_{j}}$. 
Since the parameter $B_{i}$ must be positive $m_{e}^{i}$ being positive at low pressures, and the partial pressures $P_{i}$ are monotonic increasing function of $P_{T}$, the Langmuir isotherm does not show a maximun and is not convenient to represent the adsorption isotherms of $\mathrm{H}_{2}$ in the $\mathrm{H}_{2}$ $\mathrm{CO}_{2}$ mixture, for $d=1.0$ and $2.5 \mathrm{~nm}$, and $H_{2}-C_{4}$ mixture, for $d=1.0 \mathrm{~nm}$, where $m_{e}^{H_{2}}$ decreases when the partial pressures increase. For an identical reason, the isotherm of $\mathrm{CH}_{4}$ for $d=1.0 \mathrm{~nm}$ cannot be described by a Langmuir isotherm. The occurence of a capillary condensation precludes the use of the Langmuir isotherms for describing the adsorption of $\mathrm{CO}_{2}-\mathrm{CH}_{4}$ mixture when $d=2.5 \mathrm{~nm}$. A fit of the adsorption of $\mathrm{H}_{2}-\mathrm{CH}_{4}$ mixture for $d=2.5 \mathrm{~nm}$ by the Langmuir isotherms is possible as it is shown in Fig. 10. This result agrees with the density profiles of $\mathrm{H}_{2}$ and $\mathrm{CH}_{4}$ plotted in Fig. 6 and 8 which, in accordance with the Langmuir approach hypotheses, correspond to mono-layers of adsorbed molecules in equilibrium with the gas bulk phase.

\section{CONCLUSION}

The analysis of the GCMC simulation results of the adsorption of pure gases and binary mixtures in a pore model of GNF shows the diversity of the adsorption processes which are induced by the interplay between properties of adsorbent surface and pore sizes. From the range of the van der Waals interactions, it results that the adsorbed molecules are located in a layer having an extent smaller than $0.5 \mathrm{~nm}(0.3-0.45 \mathrm{~nm})$ as it is seen in Figs. 2, 3 and 5-8. In pores of small size ( $\simeq 1.0 \mathrm{~nm}$ ), the localization of adsorbed molecules near pore surfaces and excluded volume effects between molecules leads for the gases having a strong interaction with the adsorbent to the saturation of the adsorption at high pressures. In pore of size equal 2.0-3.0 nm, at $\simeq 5.0-10.0 \mathrm{MPa}$, the layer of adsorbed molecules of gases strongly interacting with adsorbent becomes dense. The gas molecules which interact with this dense layer of adsorbed molecules induce the onset of a second layer (cf. $\mathrm{CH}_{4}$ profile Fig. 3) or generate a capillary condensation (cf. $\mathrm{CO}_{2}$ profile Fig. 3). In this latter case the isotherm adsorption is similar to an isotherm of type II.

These different adsorption processes also exist in the mixtures. For the binary mixtures considered in this work, the main feature is that the adsorption of gas interacting the most strongly with adsorbent can preclude the adsorption of the other component. The adsorption depletion of the weakly interacting gas is manifest from $H_{2}$ profiles in Fig. 7 and 8. In 
particular, the depletion is strong when a capillary condensation occurs. The main consequence of this result is that the selectivities computed from the adsorption data of pure gases can be a poor estimate of the selectivities in the mixtures. The simulation data clearly show that the adsorption and separation properties of a porous material at a macroscopic scale result from adsorption processes which, at a microscopic scale, differ markedly in particular with the pore size and pressure. This fact should be taken into account in the choice of the most adequate material for perfoming the separation of mixture components at a given thermodynamic state.

[1] R. T. Yang, Gas Separation by Adsorption processes (Imperial College Press, London, 1997).

[2] A. Yamasaki, J. Chem. Eng. Jpn., 36361 (2003).

[3] M. S. Dresselhaus, G. Dresselhaus, and P.C. Eklund, The Science of Fullerenes and Carbon Nanotubes (Academic Press, New York, 1996).

[4] M. S. Dresselhaus, K. A. Williams, and P. C. Eklund, MRS Bull. 24, 45 (1999).

[5] F. Darkrim-Lamari, P. Malbrunot, and G. Tartaglia, Int. J. Hydrogen Energy 27, 193 (2002).

[6] K. Atkinson, S. Roth, M. Hirsher, and W. Grunwald, Fuel Cells Bulletin 4, 9 (2001).

[7] M. Hirscher, M. Becher, M. Haluska, F. von Zeppelin, X. Chen, U. Dettlaff-Weglikowska, and S. Roth, Alloys Compd. 356, 433 (2003).

[8] D. Lozano, M. A. De la Casa, J. Alcaniz, D. Cazorla, and A. Linares, Fuel 81, 1777 (2002).

[9] D. Lozano, D. Cazorla, A. Linares, and D. F. Quinn, Carbon 40, 989 (2002).

[10] D. Nicholson and K. E. Gubbins, J. Chem. Phys. 104, 8126 (1996).

[11] M. M. Calbi, S. M. Gatica, M. J. Bojan, and M. W. Cole, J. Chem. Phys. 115, 9975 (2001).

[12] M. M. Calbi, M. W. Cole, S. M. Gatica, M. J. Bojan, and G. Stan, Rev. Mod. Phys. 73, 857 (2001).

[13] F. Darkrim and D. Levesque, J. Chem. Phys. 109, 4981 (1998).

[14] Q. Wang and J. K. Johnson, J. Phys. Chem. B 103, 277 (1999).

[15] Q. Wang, S. R. Challa, D. S. Sholl, and J. K. Johnson, Phys. Rev. Lett. 82, 956 (1999).

[16] Q. Wang and J. K. Johnson, J. Chem. Phys. 110, 577 (1999).

[17] W. Shi and J. K. Johnson, Phys. Rev. Lett. 91, 015504 (2003).

[18] C. Matranga, L. Chen, M. Smith, E. Bittner, J. K. Johnson, and B. Bockrath, J. Phys. Chem. 
B 107, 12930 (2003).

[19] X. Shao, W. Wang, R. Xue, and Z. Shen, J. Phys. Chem. B 108, 2970 (2004).

[20] P.Guay, B. L. Stasfield and A. Rochefort, Carbon 42, 2187 (2004).

[21] M. Rzepka, R. Lamp, and M. A. dela Cassa-Lillo, Phys. Chem. B 102, 10894 (1998).

[22] K. A. Williams and P. C. Eklund, Chem. Phys. Lett. 320, 352 (2000).

[23] D. Cao and J. Wu Carbon 43, 1364 (2005).

[24] M. Heuchel, G. M. Davies, E. Buss, and N. A. Seaton, Langmuir 15, 8695 (1999).

[25] M. C. Blanco Lopez, A. Martinez-Alonso, and J.M.D. Tascon, Carbon 38, 1177 (2000).

[26] N. M. Rodriguez, A. Chambers, and R. T. K. Baker, Langmuir 11, 3862 (1995).

[27] T. Zecho, A. Guttler, and J. Kuppers, Carbon 42609 (2004).

[28] S. Kayiran, F. Darkrim-Lamari, and D. Levesque, J. Phys. Chem. B. 108, 15211 (2004).

[29] A. C. Dillon, K. M. Jones, T. A. Bekkedahl, C. H. Kiang, D. S. Bethune, and M. J. Heben, Nature 386, 377 (1997).

[30] M. Becher, M. Haluska, M. Hirscher, A. Quintel, V. Skakalova, U. Dettlaff-Weglikovska, X. Chen, M. Hulman, Y. Choi, S. Roth, V. Meregalli, M. Parrinello, R. Strobel, L. Jorissen, M. M. Kappes, J. Fink, A. Zuttel, I. Stepanek, and P. Bernier, C.R. Physique 4, 1055 (2003).

[31] S.K. Nath, B. J. Banaszak, and J. J. de Pablo, J. Chem. Phys. 114, 3612 (2001).

[32] J.G. Harris and K. H. Yung, J. Phys. Chem. 99, 12021 (1995).

[33] J.M. Stubbs and J.I. Siepmann, J. Chem. Phys. 121, 1525 (2004).

[34] C.G. Gray and K.E. Gubbins, Theory of Molecular Fluids, Volume 1: Fundamentals (Clarendon, Oxford, 1984).

[35] R.L. Bond, ed., Porous Carbon Solids (Academic Press, New York, 1967).

[36] S. Brunauer, L. Deming, W. Deming and E. Teller, J. Am. Chem. Soc.62, 1723 (1940).

[37] P. Malbrunot, D. Vidal, J. Vermesse, R. Chahine, and T. K. Bose, Langmuir 13, 539 (1997).

[38] B. Weinberger, F. Darkrim Lamari, S. Beyaz Kayiran, A. Gicquel, and D. Levesque, AIChE J. 51, 142 (2005).

[39] I. Langmuir, J. Amer. Chem. Soc. 40, 1361 (1918). 


\section{Figure Captions}

Fig. 1. Snapshot of $\mathrm{H}_{2}-\mathrm{CO}_{2}$ mixture in the simulation cell of sides $L_{y}=4.18 \mathrm{~nm}$ and $L_{z}=5.36 \mathrm{~nm}$ with a slit of width $d=2.5 \mathrm{~nm}$ and stack lateral extent $D=1.1 \mathrm{~nm}$ in the x-direction, at $293 \mathrm{~K}$ and pressure of $10.0 \mathrm{MPa}$. Blue dots : $H_{2}$ molecule, green dots : $\mathrm{CO}_{2}$ molecule, yellow dots $\mathrm{CH}$ group. The red lines link next neighborings $\mathrm{C}$ atoms or $\mathrm{CH}$ groups in a graphene sheet

Fig. 2. Adsorption density profiles (filled circle and dashed-line) of pure gases $\left(\mathrm{mmol} / \mathrm{cm}^{3}\right)$ in a slit of width $d=1.0 \mathrm{~nm}$ at $293 \mathrm{~K}$ for pressures of $0.5 \mathrm{MPa}$ (left column) and 5.0 MPa (right column), from top to bottom $\mathrm{H}_{2}, \mathrm{CO}_{2}$ and $\mathrm{CH}_{4}$. Horizontal dashed lines : bulk density of gases.

Fig. 3. Adsorption density profiles (filled circle and dashed-line) of pure gases $\left(\mathrm{mmol} / \mathrm{cm}^{3}\right)$ in a slit of width $d=2.5 \mathrm{~nm}$ at $293 \mathrm{~K}$ for pressures of $0.5 \mathrm{MPa}$ (left column) and 5.0 $\mathrm{MPa}$ (right column), from top to bottom $\mathrm{H}_{2}, \mathrm{CO}_{2}$ and $\mathrm{CH}_{4}$. Horizontal dashed lines : bulk density of gases.

Fig. 4. Selectivity $S_{e}^{i, j}$ as defined in Sect. III for pures gases at $293 \mathrm{~K}$ versus pressure (MPa) in a slit of width $d=1.0 \mathrm{~nm}$ (bottom) and $2.5 \mathrm{~nm}$ (top) : $S_{e}^{C O_{2}, H_{2}}$ filled black circle and dashed line, $\mathrm{S}_{e}^{\mathrm{CH}_{4}, \mathrm{H}_{2}}$ filled red square and dashed line, $\mathrm{S}_{e}^{\mathrm{CO}_{2}, \mathrm{CH}_{4}}$ filled green diamond and dashed line.

Fig. 5. Adsorption density profiles of components (filled circle and dashed-line) of equimolar binary mixtures $\left(\mathrm{mmol} / \mathrm{cm}^{3}\right)$ in a slit of width $d=1.0 \mathrm{~nm}$ at $293 \mathrm{~K}$ for a pressure of $1.0 \mathrm{MPa}$. From top to bottom, $\mathrm{H}_{2}-\mathrm{CO}_{2}$ mixture : left column $\mathrm{H}_{2}$ density profile and right column $\mathrm{CO}_{2}$ density profile ; $\mathrm{CH}_{4}-\mathrm{CO}_{2}$ mixture : left column $\mathrm{CH}_{4}$ density profile and right column $\mathrm{CO}_{2}$ density profile ; $\mathrm{H}_{2}-\mathrm{CH}_{4}$ mixture : left column $\mathrm{H}_{2}$ density profile and right column $\mathrm{CH}_{4}$ density profile. Horizontal dashed lines : bulk density of mixture components.

Fig. 6. Adsorption density profiles of components (filled circle and dashed-line) of equimolar binary mixtures $\left(\mathrm{mmol} / \mathrm{cm}^{3}\right)$ in a slit of width $d=2.5 \mathrm{~nm}$ at $293 \mathrm{~K}$ for a pressure of 1.0 MPa. From top to bottom, $\mathrm{H}_{2}-\mathrm{CO}_{2}$ mixture : left column $\mathrm{H}_{2}$ density profile and right column $\mathrm{CO}_{2}$ density profile ; $\mathrm{CH}_{4}-\mathrm{CO}_{2}$ mixture : left column $\mathrm{CH}_{4}$ density profile and right column $\mathrm{CO}_{2}$ density profile ; $\mathrm{H}_{2}-\mathrm{CH}_{4}$ mixture : left column $\mathrm{H}_{2}$ density profile and right column $\mathrm{CH}_{4}$ density profile. Horizontal dashed lines : bulk density of mixture components.

Fig. 7. Adsorption density profiles of components (filled circle and dashed-line) of equimolar binary mixtures $\left(\mathrm{mmol} / \mathrm{cm}^{3}\right)$ in a slit of width $d=1.0 \mathrm{~nm}$ at $293 \mathrm{~K}$ for a pressure of 
10.0 MPa. From top to bottom, $\mathrm{H}_{2}-\mathrm{CO}_{2}$ mixture : left column $\mathrm{H}_{2}$ density profile and right column $\mathrm{CO}_{2}$ density profile ; $\mathrm{CH}_{4}-\mathrm{CO}_{2}$ mixture : left column $\mathrm{CH}_{4}$ density profile and right column $\mathrm{CO}_{2}$ density profile ; $\mathrm{H}_{2}-\mathrm{CH}_{4}$ mixture : left column $\mathrm{H}_{2}$ density profile and right column $\mathrm{CH}_{4}$ density profile. Horizontal dashed lines : bulk density of mixture components.

Fig. 8. Adsorption density profiles of components (filled circle and dashed-line) of equimolar binary mixtures $\left(\mathrm{mmol} / \mathrm{cm}^{3}\right)$ in a slit of width $d=2.5 \mathrm{~nm}$ at $293 \mathrm{~K}$ for a pressure of 10.0 MPa. From top to bottom, $\mathrm{H}_{2}-\mathrm{CO}_{2}$ mixture : left column $\mathrm{H}_{2}$ density profile and right column $\mathrm{CO}_{2}$ density profile ; $\mathrm{CH}_{4}-\mathrm{CO}_{2}$ mixture : left column $\mathrm{CH}_{4}$ density profile and right column $\mathrm{CO}_{2}$ density profile ; $\mathrm{H}_{2}-\mathrm{CH}_{4}$ mixture : left column $\mathrm{H}_{2}$ density profile and right column $\mathrm{CH}_{4}$ density profile. Horizontal dashed lines : bulk density of mixture components.

Fig. 9. Excess adsorption $m_{e}^{i}$ for binary mixtures in a slit of width $d=1.0 \mathrm{~nm}$ at 293 $\mathrm{K}$ versus pressure (MPa). From top to bottom $\mathrm{H}_{2}-\mathrm{CO}_{2}$ mixture : left column blue circles and dashed line $\mathrm{H}_{2}$, right column red circles and dashed line $\mathrm{CO}_{2} ; \mathrm{H}_{2}-\mathrm{CH}_{4}$ mixture : left column blue squares and dashed line $\mathrm{H}_{2}$, right column green squares and dashed line $\mathrm{CH}_{4}$, $\mathrm{CH}_{4}-\mathrm{CO}_{2}$ mixture : left column green diamonds and dashed line $\mathrm{CH}_{4}$, right column red diamonds and dashed line $\mathrm{CO}_{2}$.

Fig. 10. Excess adsorption $m_{e}^{i}$ for binary mixtures in a slit of width $d=2.5 \mathrm{~nm}$ at $293 \mathrm{~K}$ versus pressure (MPa). From top to bottom $\mathrm{H}_{2}-\mathrm{CO}_{2}$ mixture : left column blue circles and dashed line $\mathrm{H}_{2}$, right column red circles and dashed line $\mathrm{CO}_{2} ; \mathrm{H}_{2}-\mathrm{CH}_{4}$ mixture : left column blue squares and dashed line $\mathrm{H}_{2}$, right column green squares and dashed line $\mathrm{CH}_{4}$, black dashed-line fit by a Langmuir isotherm; $\mathrm{CH}_{4}-\mathrm{CO}_{2}$ mixture : left column green diamonds and dashed line $\mathrm{CH}_{4}$, right column red diamonds and dashed line $\mathrm{CO}_{2}$.

Fig. 11. At $293 \mathrm{~K}$ in a slit of width $d=5.0 \mathrm{~nm}$ adsorption density profiles $\left(\mathrm{mmol} / \mathrm{cm}^{3}\right)$ : top, at $P_{T}=5.0 \mathrm{MPa}$, right column pure $H_{2}$ (filled blue circle and dashed line) and left column pure $\mathrm{CO}_{2}$ (filled red circle and dashed line), bottom, at $P_{T}=10.0 \mathrm{MPa}$, components of $\mathrm{H}_{2}-\mathrm{CO}_{2}$ equimolar mixture filled blue circle and dashed line $\mathrm{H}_{2}$ and filled red circle and dashed line $\mathrm{CO}_{2}$. Horizontal dashed lines : bulk density of pure gases and mixture components.

Fig. 12. Excess adsorption $m_{e}^{i}(\mathrm{mmol} / \mathrm{gr})$ versus pressure (MPa) at $293 \mathrm{~K}$ for pure gases in slits of width $d=1.0 \mathrm{~nm}$ (left column) and $2.5 \mathrm{~nm}$ (right column). Dashed-dotted line fit by a Langmuir isotherm of GCMC data, filled circle : $\mathrm{H}_{2}$, filled square : $\mathrm{CO}_{2}$ and filled diamond : $\mathrm{CH}_{4}$. 


\section{Table Captions}

Table I. Parameter $\epsilon$ (degree K) and $\sigma(\AA)$ of LJ potentials of gas molecules and GNF $C$ atoms or $C H$ chemical groups. $l(\AA)$ distance to molecule center of mass along the symmetry molecular axis of the effective charges $q$ (unit of electron charge) associated to $\mathrm{H}_{2}$ and $\mathrm{CO}_{2}$ quadrupoles.

Table II. Adsorption of pure gases. $P_{T}$ total pressure $(\mathrm{MPa}), d_{B}$ bulk density of gases $\left(\mathrm{mmol} / \mathrm{cm}^{3}\right), m_{a}^{i}$ and $m_{e}^{i}$ total and excess adsorption (mmol/gr), $S_{p}^{i, j}$ selectivity. Column 3 , 4 and 5 results for a slit of width $d=1.0 \mathrm{~nm}$, column 6,7 and 8 results for a slit of width $d=2.5 \mathrm{~nm}$.

Table III. Adsorption of binary equimolar mixtures. $P_{T}$ total pressure $(\mathrm{MPa})$. Column 2 and 3 partial pressure of mixture components (MPa). Column 4, 5 and 6 : total adsorption of mixture components $(\mathrm{mmol} / \mathrm{gr})$ and selectivity for a slit of width $d=1.0 \mathrm{~nm}$. Column 7, 8 and 9 total adsorption of mixture components $(\mathrm{mmol} / \mathrm{gr})$ and selectivity for a slit of width $d=2.5 \mathrm{~nm}$. 
TABLE I:

\begin{tabular}{|c|c|c|c|c|}
\hline Atom/Molecule & $\epsilon$ & $\sigma$ & $q$ & $l$ \\
\hline$H_{2}$ & 36.7 & 2.958 & 0.483 & 0.3705 \\
\hline$C H_{4}$ & 148.2 & 3.817 & - & - \\
\hline$O_{C O_{2}}$ & 79.0 & 3.05 & -0.35 & 1.160 \\
\hline$C_{C O_{2}}$ & 27.0 & 2.80 & 0.70 & 0.00 \\
\hline \hline$C_{G N F}$ & 28.0 & 3.400 & - & - \\
\hline$C H_{G N F}$ & 46.0 & 3.770 & - & - \\
\hline
\end{tabular}


TABLE II:

\begin{tabular}{|c|c|c|c|c|c|c|c|}
\hline \multicolumn{8}{|c|}{$H_{2}$} \\
\hline $\mathrm{P}_{T}$ & $d_{B}$ & $m_{a}^{H_{2}}$ & $m_{e}^{H_{2}}$ & $S_{p}^{C O_{2}, H_{2}}$ & $m_{a}^{H_{2}}$ & $m_{e}^{H_{2}}$ & $S_{p}^{C O_{2}, H_{2}}$ \\
\hline 0.05 & 0.020 & 0.021 & 0.014 & 14.2 & 0.037 & 0.016 & 5.8 \\
\hline 0.25 & 0.103 & 0.084 & 0.050 & 21.7 & 0.163 & 0.059 & 5.8 \\
\hline 0.5 & 0.205 & 0.167 & 0.098 & 29.6 & 0.322 & 0.114 & 5.8 \\
\hline 1.5 & 0.603 & 0.477 & 0.270 & 16.7 & 0.892 & 0.281 & 6.9 \\
\hline 2.6 & 1.091 & 0.846 & 0.473 & 10.2 & 1.67 & 0.565 & 6.2 \\
\hline 4.9 & 1.989 & 1.48 & 0.808 & 6.1 & 2.99 & 0.976 & 7.9 \\
\hline \multicolumn{8}{|c|}{$\mathrm{CO}_{2}$} \\
\hline $\mathrm{P}_{T}$ & $d_{B}$ & $m_{a}^{C O_{2}}$ & $m_{e}^{C O_{2}}$ & $S_{p}^{C O_{2}, C H_{4}}$ & $m_{a}^{C O_{2}}$ & $m_{e}^{C O_{2}}$ & $S_{p}^{C O_{2}, C H_{4}}$ \\
\hline 0.05 & 0.020 & 0.299 & 0.292 & 1.8 & 0.214 & 0.194 & 1.7 \\
\hline 0.25 & 0.103 & 1.82 & 1.79 & 2.1 & 0.944 & 0.839 & 1.5 \\
\hline 0.5 & 0.205 & 4.94 & 4.87 & 2.9 & 1.88 & 1.67 & 1.6 \\
\hline 1.5 & 0.663 & 7.99 & 7.76 & 1.9 & 6.17 & 5.49 & 1.9 \\
\hline 2.5 & 1.168 & 8.60 & 8.20 & 1.7 & 10.4 & 9.21 & 2.1 \\
\hline 4.9 & 2.834 & 9.13 & 8.16 & 1.4 & 23.5 & 20.64 & 2.9 \\
\hline \multicolumn{8}{|c|}{$\mathrm{CH}_{4}$} \\
\hline $\mathrm{P}_{T}$ & $d_{B}$ & $m_{a}^{C H_{4}}$ & $m_{e}^{C H_{4}}$ & $S_{p}^{C H_{4}, H_{2}}$ & $m_{a}^{C H_{4}}$ & $m_{e}^{C H_{4}}$ & $S_{p}^{C H_{4}, H_{2}}$ \\
\hline 0.05 & 0.020 & 0.166 & 0.160 & 7.9 & 0.124 & 0.104 & 3.4 \\
\hline 0.24 & 0.103 & 0.864 & 0.831 & 10.3 & 0.618 & 0.538 & 3.8 \\
\hline 0.49 & 0.205 & 1.68 & 1.62 & 10.1 & 1.18 & 0.984 & 3.7 \\
\hline 1.5 & 0.603 & 4.11 & 3.90 & 8.6 & 3.29 & 2.65 & 3.7 \\
\hline 2.6 & 1.059 & 5.20 & 4.84 & 6.2 & 4.92 & 4.81 & 2.9 \\
\hline 5.5 & 2.265 & 6.40 & 5.63 & 4.3 & 8.18 & 5.88 & 2.7 \\
\hline
\end{tabular}


TABLE III:

\begin{tabular}{|c|c|c|c|c|c|c|c|c|}
\hline \multicolumn{9}{|c|}{$\mathrm{H}_{2}-\mathrm{CO}_{2}$ Mixture } \\
\hline $\mathrm{P}_{T}$ & $\mathrm{P}_{H_{2}}$ & $\mathrm{P}_{\mathrm{CO}_{2}}$ & $m_{a}^{H_{2}}$ & $m_{a}^{C O_{2}}$ & $S_{m}^{C O_{2}, H_{2}}$ & $m_{a}^{H_{2}}$ & $m_{a}^{C O_{2}}$ & $S_{m}^{C O_{2}, H_{2}}$ \\
\hline 0.1 & 0.05 & 0.05 & 0.02 & 0.26 & 13.0 & 0.04 & 0.22 & 5.5 \\
\hline 0.5 & 0.25 & 0.25 & 0.07 & 1.62 & 23.1 & 0.15 & 0.90 & 6.0 \\
\hline 1.0 & 0.5 & 0.5 & 0.09 & 4.69 & 52.1 & 0.30 & 1.84 & 6.1 \\
\hline 2.9 & 1.5 & 1.4 & 0.09 & 7.81 & 86.8 & 0.76 & 5.53 & 7.3 \\
\hline 5.0 & 2.6 & 2.4 & 0.11 & 8.45 & 76.8 & 1.17 & 9.17 & 7.8 \\
\hline 10.1 & 5.7 & 4.4 & 0.18 & 8.92 & 49.6 & 1.26 & 20.5 & 16.3 \\
\hline \multicolumn{9}{|c|}{$\mathrm{H}_{2}-\mathrm{CH}_{4}$ Mixture } \\
\hline $\mathrm{P}_{T}$ & $\mathrm{P}_{H_{2}}$ & $\mathrm{P}_{\mathrm{CH}_{4}}$ & $m_{a}^{H_{2}}$ & $m_{a}^{C H_{4}}$ & $S_{m}^{C H_{4}, H_{2}}$ & $m_{a}^{H_{2}}$ & $m_{a}^{C H_{4}}$ & $S_{m}^{C H_{4}, H_{2}}$ \\
\hline 0.1 & 0.05 & 0.05 & 0.020 & 0.169 & 8.5 & 0.044 & 0.169 & 3.8 \\
\hline 0.5 & 0.25 & 0.25 & 0.090 & 0.841 & 9.3 & 0.161 & 0.624 & 3.9 \\
\hline 1.0 & 0.5 & 0.5 & 0.144 & 1.65 & 11.5 & 0.310 & 1.19 & 3.8 \\
\hline 3.0 & 1.5 & 1.5 & 0.299 & 3.92 & 13.1 & 0.860 & 3.14 & 3.7 \\
\hline 5.0 & 2.5 & 2.5 & 0.391 & 4.94 & 12.6 & 1.35 & 4.63 & 3.4 \\
\hline 10.0 & 5.0 & 5.0 & 0.712 & 5.97 & 8.4 & 2.42 & 7.30 & 3.0 \\
\hline \multicolumn{9}{|c|}{$\mathrm{CH}_{4}-\mathrm{CO}_{2}$ Mixture } \\
\hline $\mathrm{P}_{T}$ & $\mathrm{P}_{\mathrm{CO}_{2}}$ & $\mathrm{P}_{\mathrm{CH}_{4}}$ & $m_{a}^{C H_{4}}$ & $m_{a}^{C O_{2}}$ & $S_{m}^{C O_{2}, \mathrm{CH}_{4}}$ & $m_{a}^{C H_{4}}$ & $m_{a}^{C O_{2}}$ & $S_{m}^{C O_{2}, C H_{4}}$ \\
\hline 0.1 & 0.05 & 0.05 & 0.253 & 0.389 & 1.5 & 0.176 & 0.255 & 1.4 \\
\hline 0.5 & 0.25 & 0.25 & 0.961 & 2.15 & 2.2 & 0.718 & 0.929 & 1.3 \\
\hline 1.0 & 0.5 & 0.5 & 1.40 & 3.87 & 2.8 & 1.16 & 1.85 & 1.6 \\
\hline 3.0 & 1.6 & 1.4 & 1.33 & 5.87 & 4.4 & 2.74 & 5.17 & 1.9 \\
\hline 5.0 & 2.7 & 2.3 & 1.58 & 6.59 & 4.2 & 3.88 & 7.96 & 2.0 \\
\hline 10.2 & 5.88 & 4.36 & 1.71 & 6.95 & 4.1 & 5.64 & 13.3 & 2.4 \\
\hline
\end{tabular}




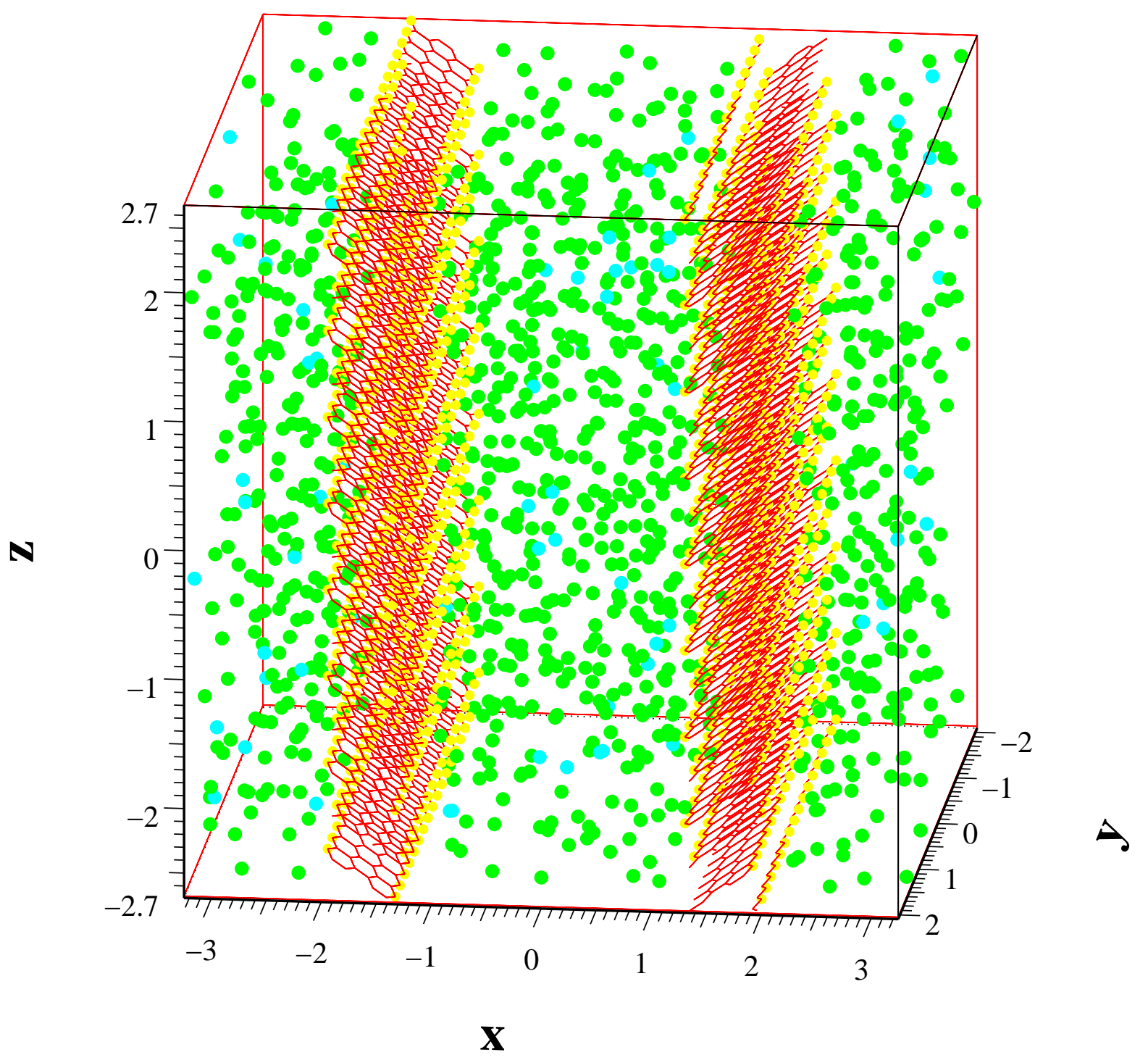

FIG. 1: 


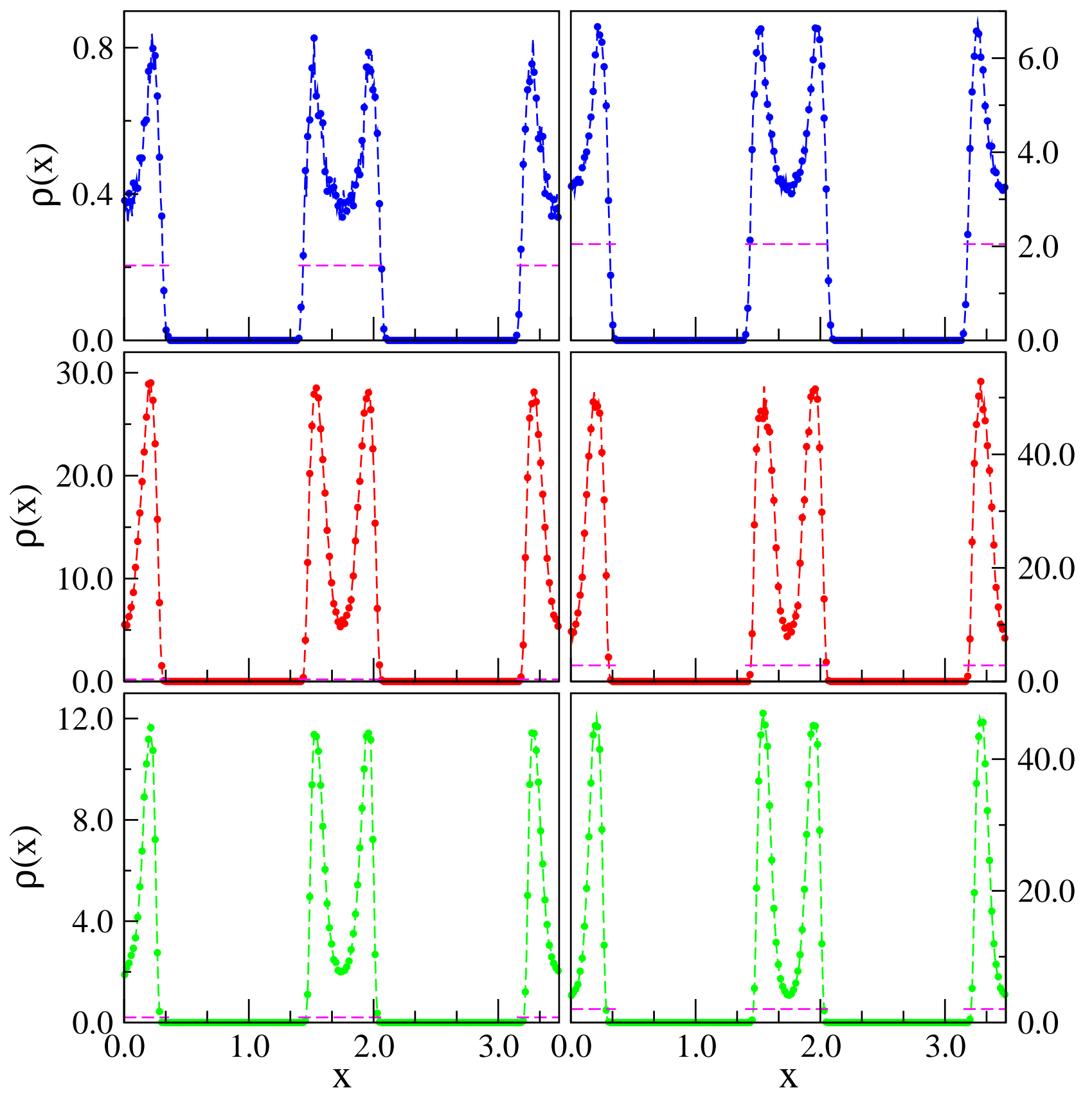

FIG. 2: 


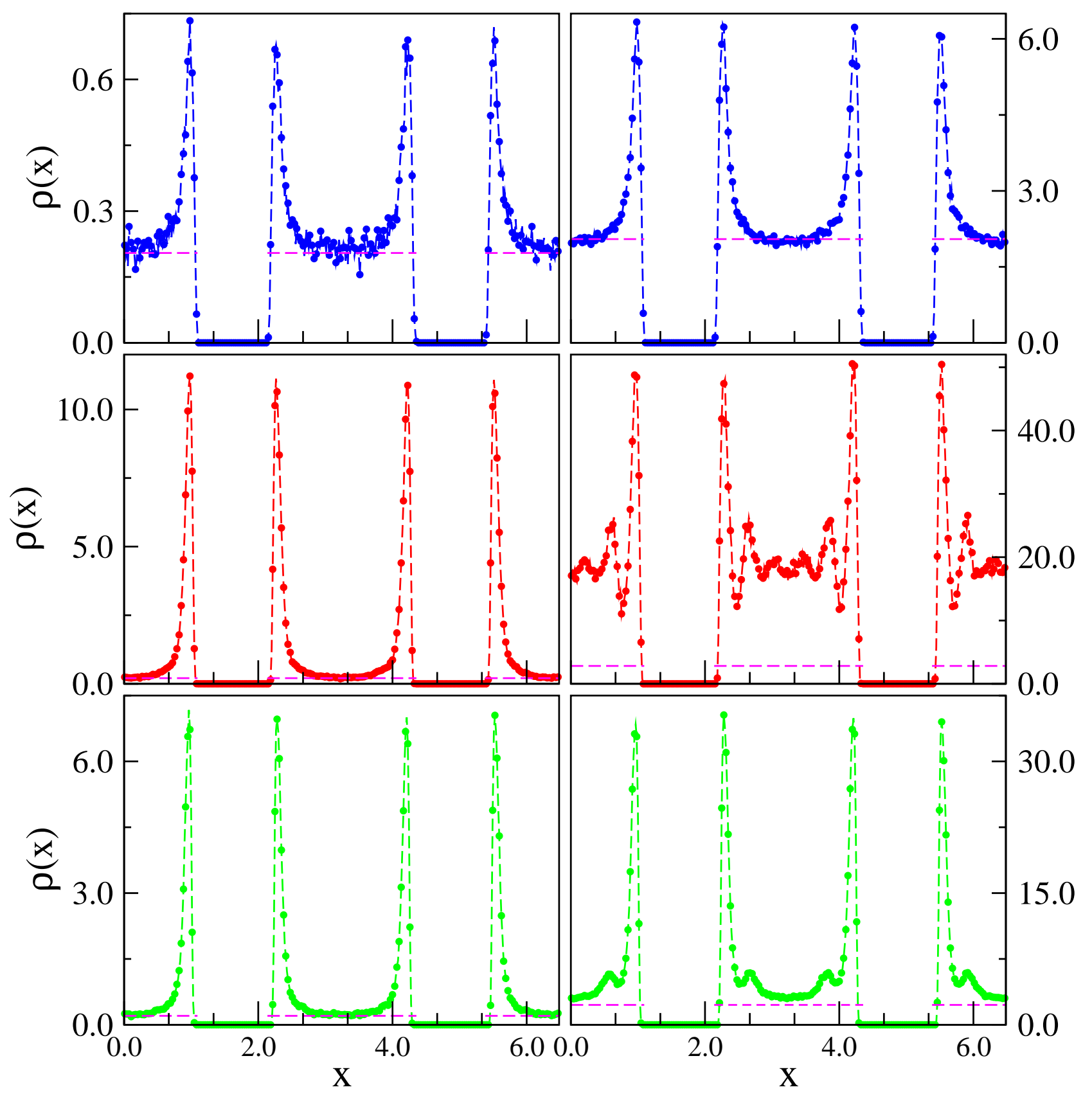

FIG. 3: 

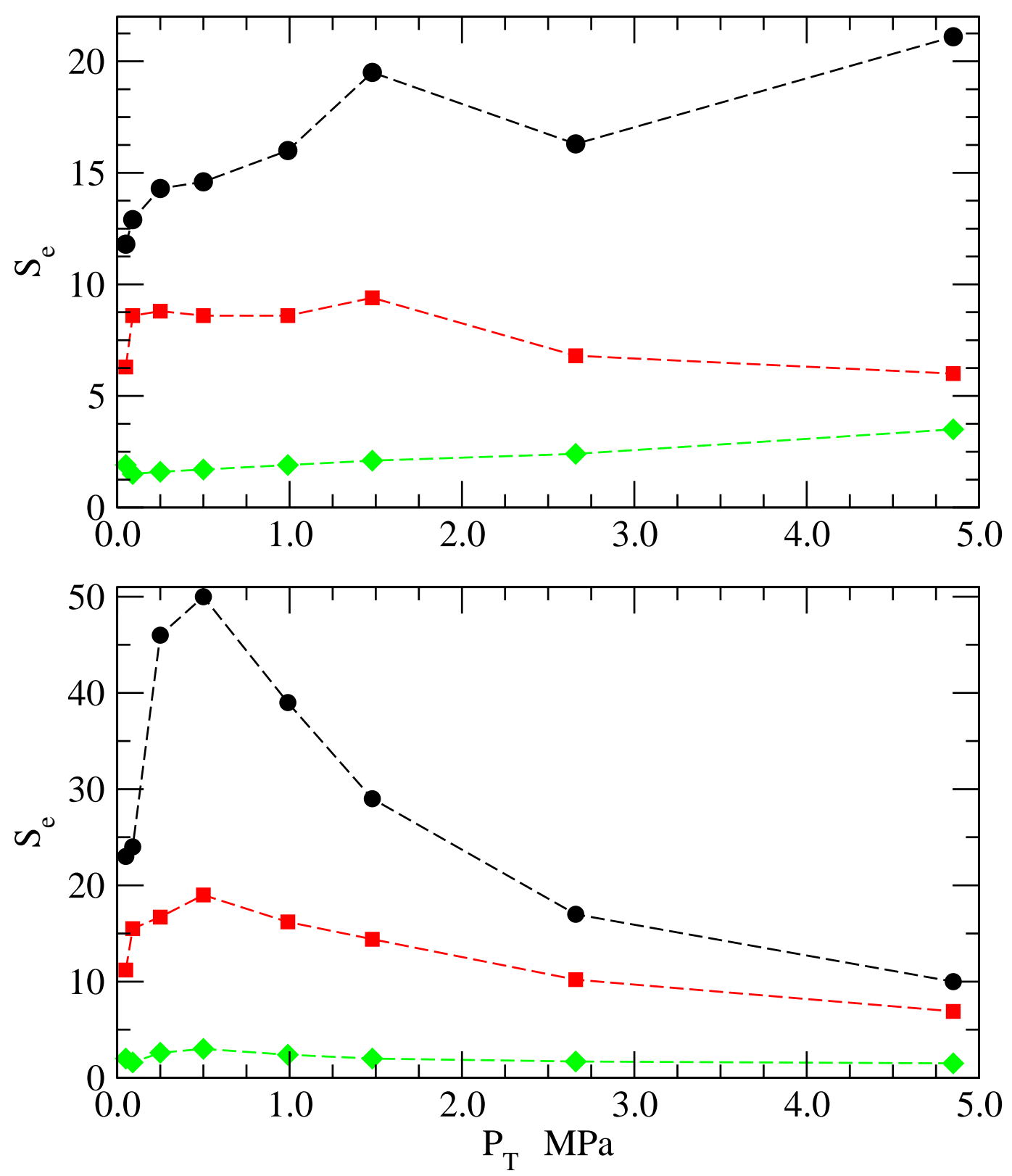

FIG. 4: 


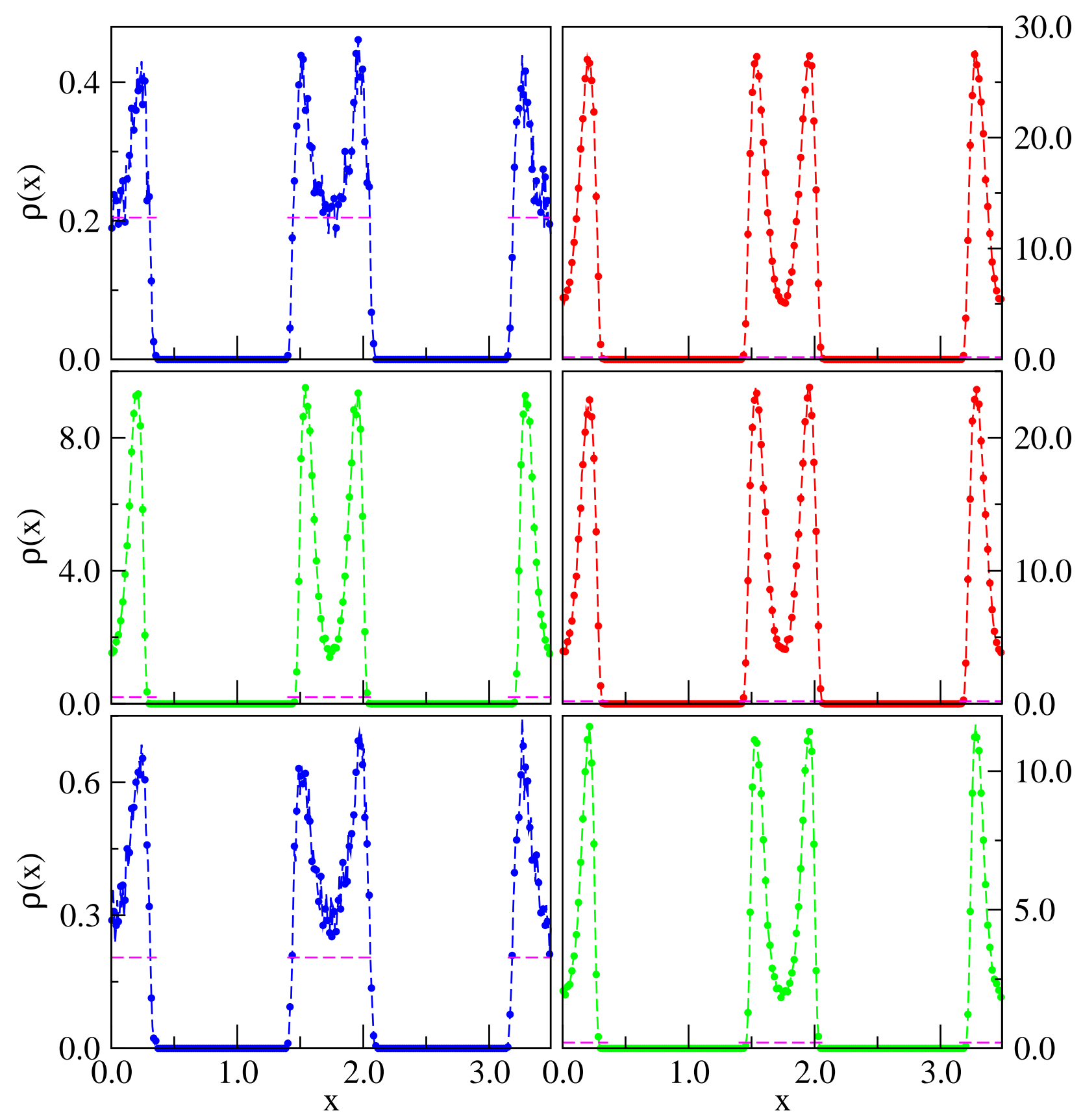

FIG. 5: 


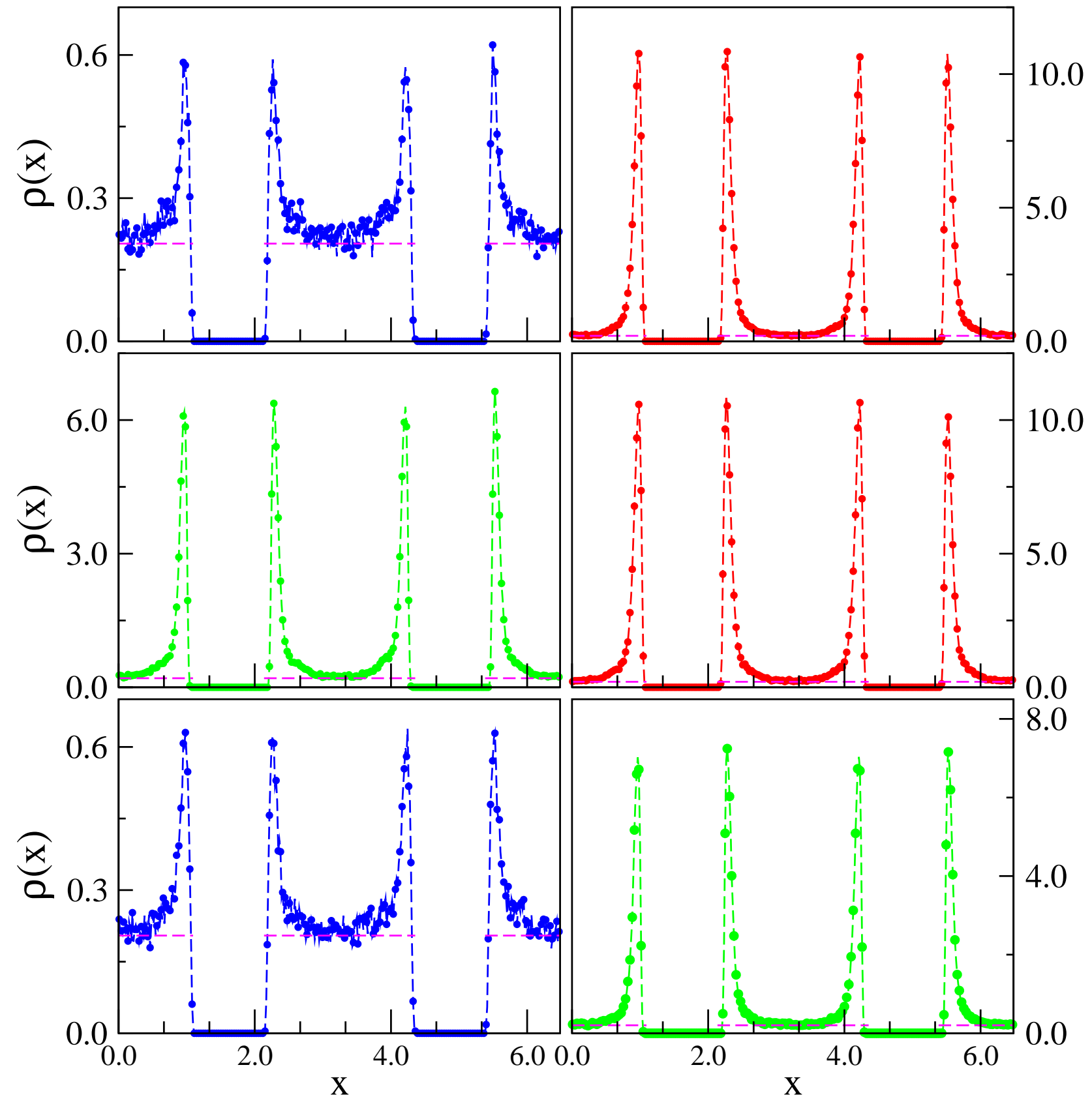

FIG. 6: 


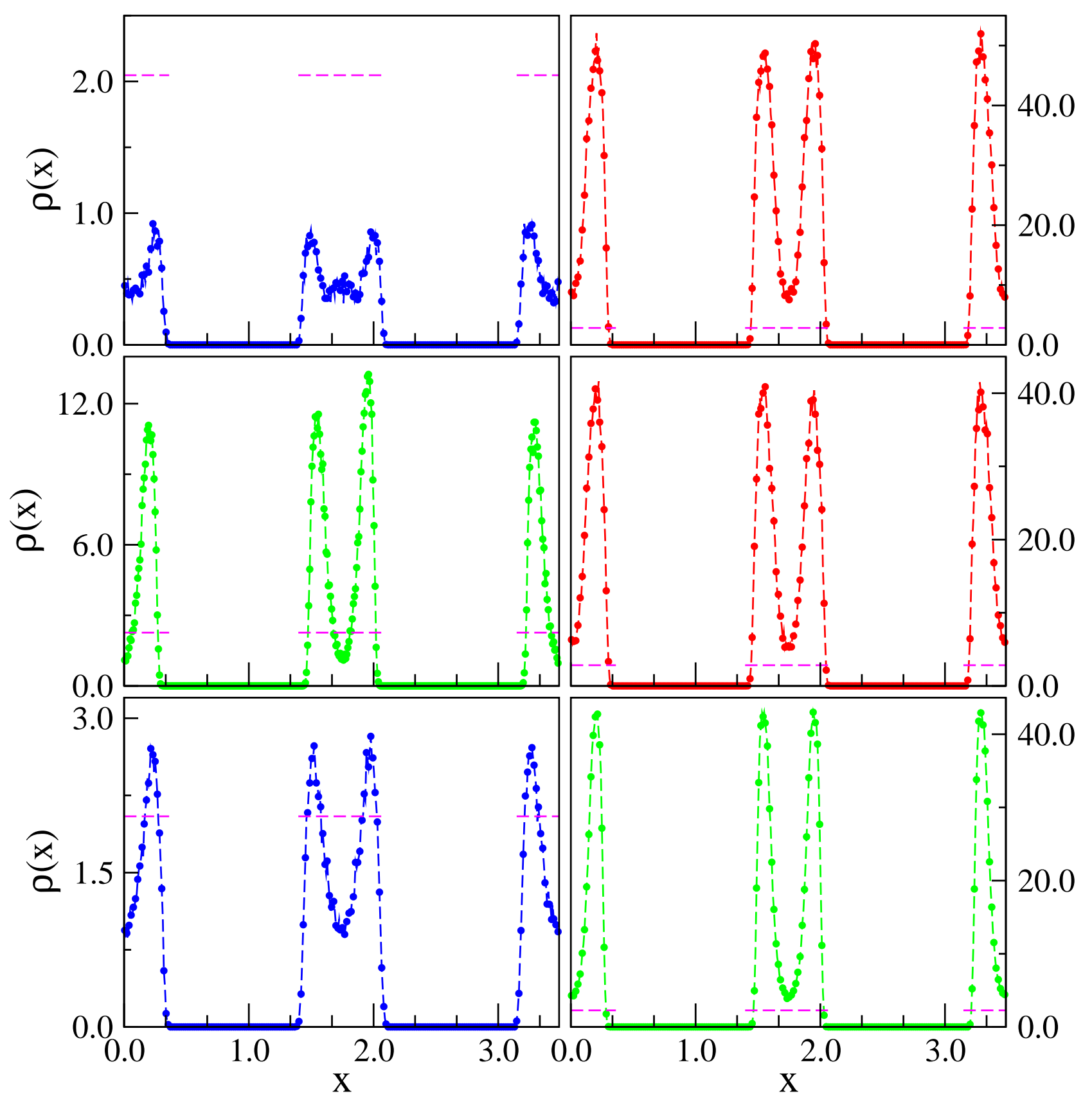

FIG. 7: 


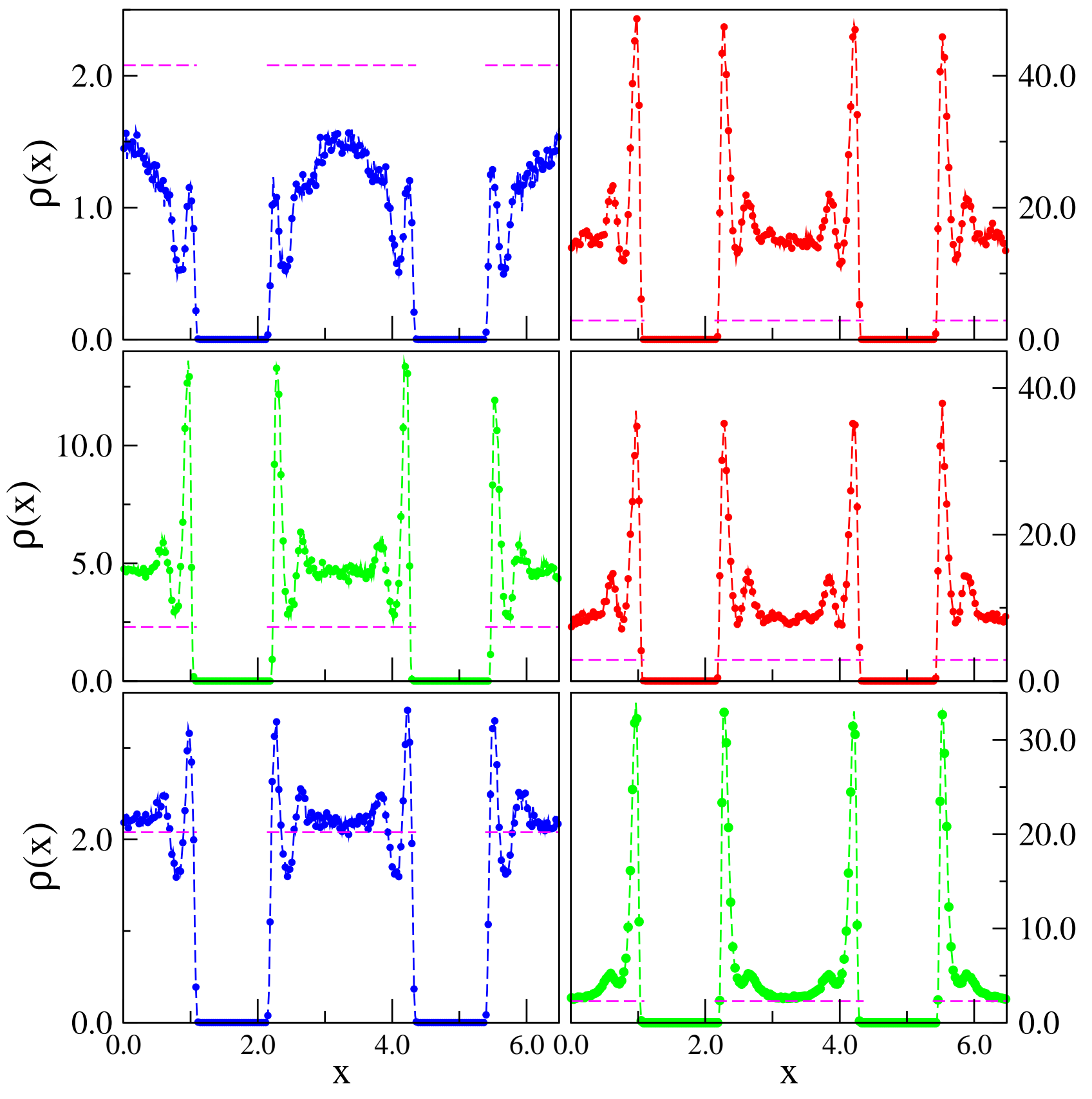

FIG. 8: 

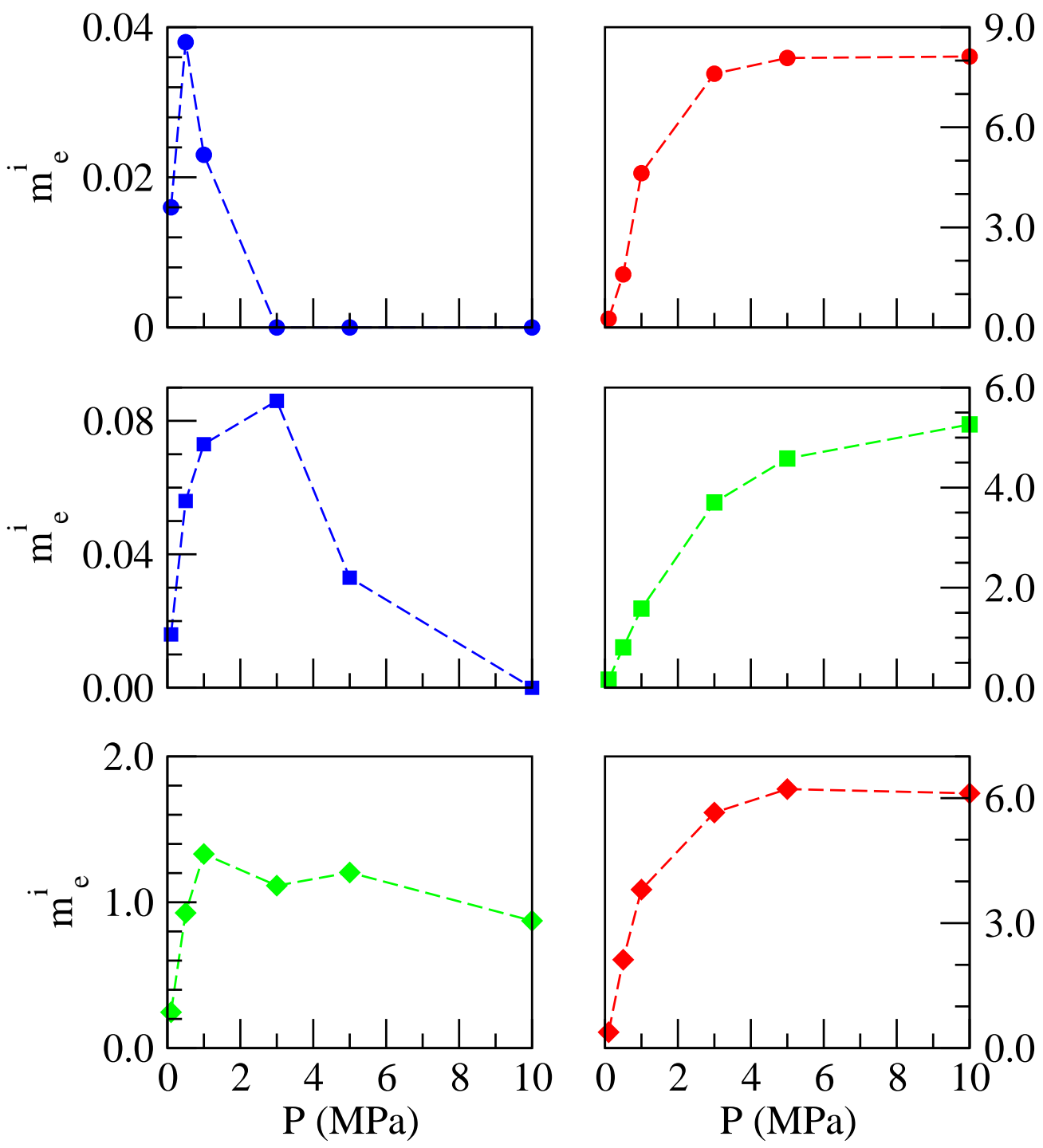

FIG. 9: 

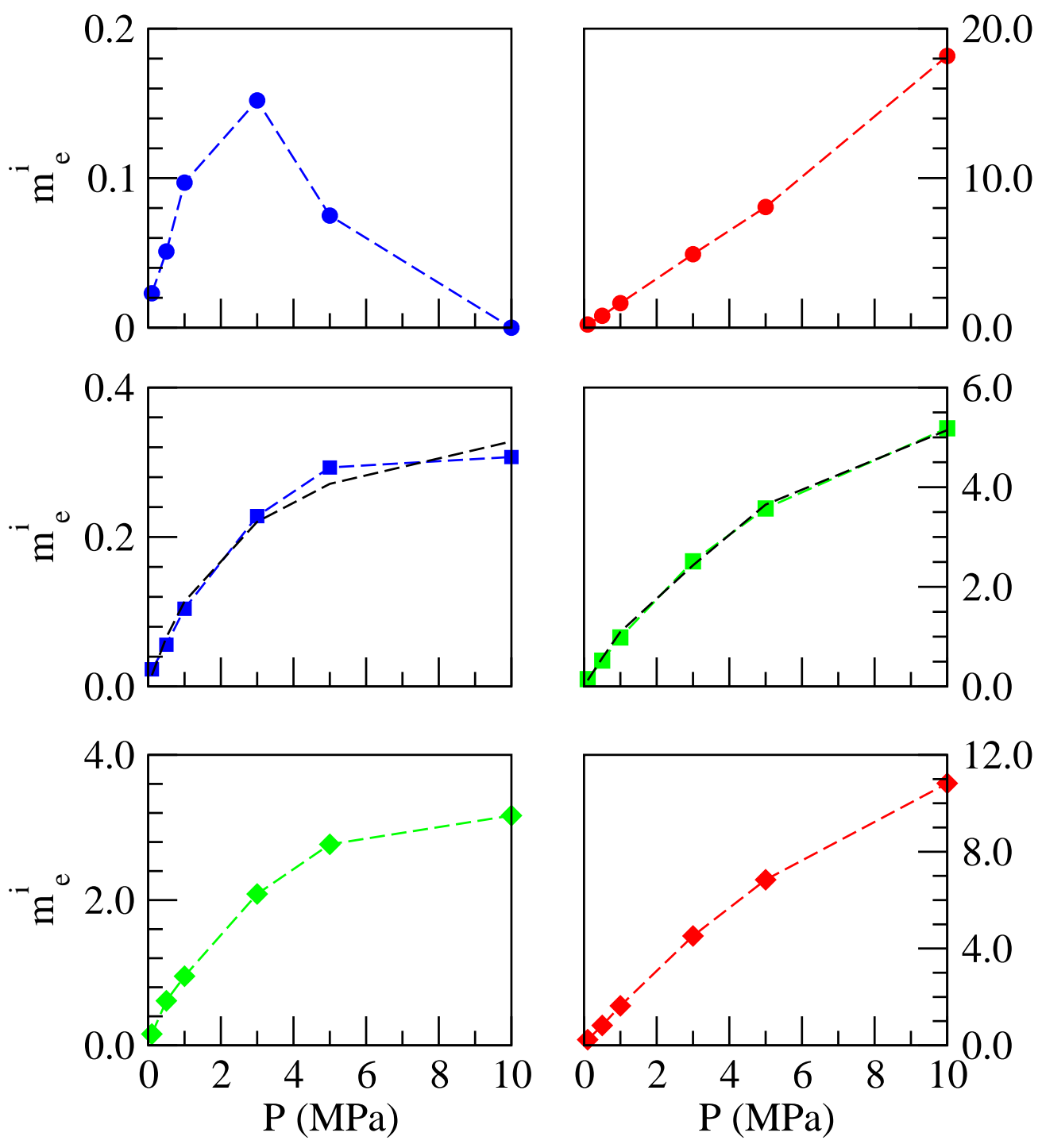

FIG. 10: 

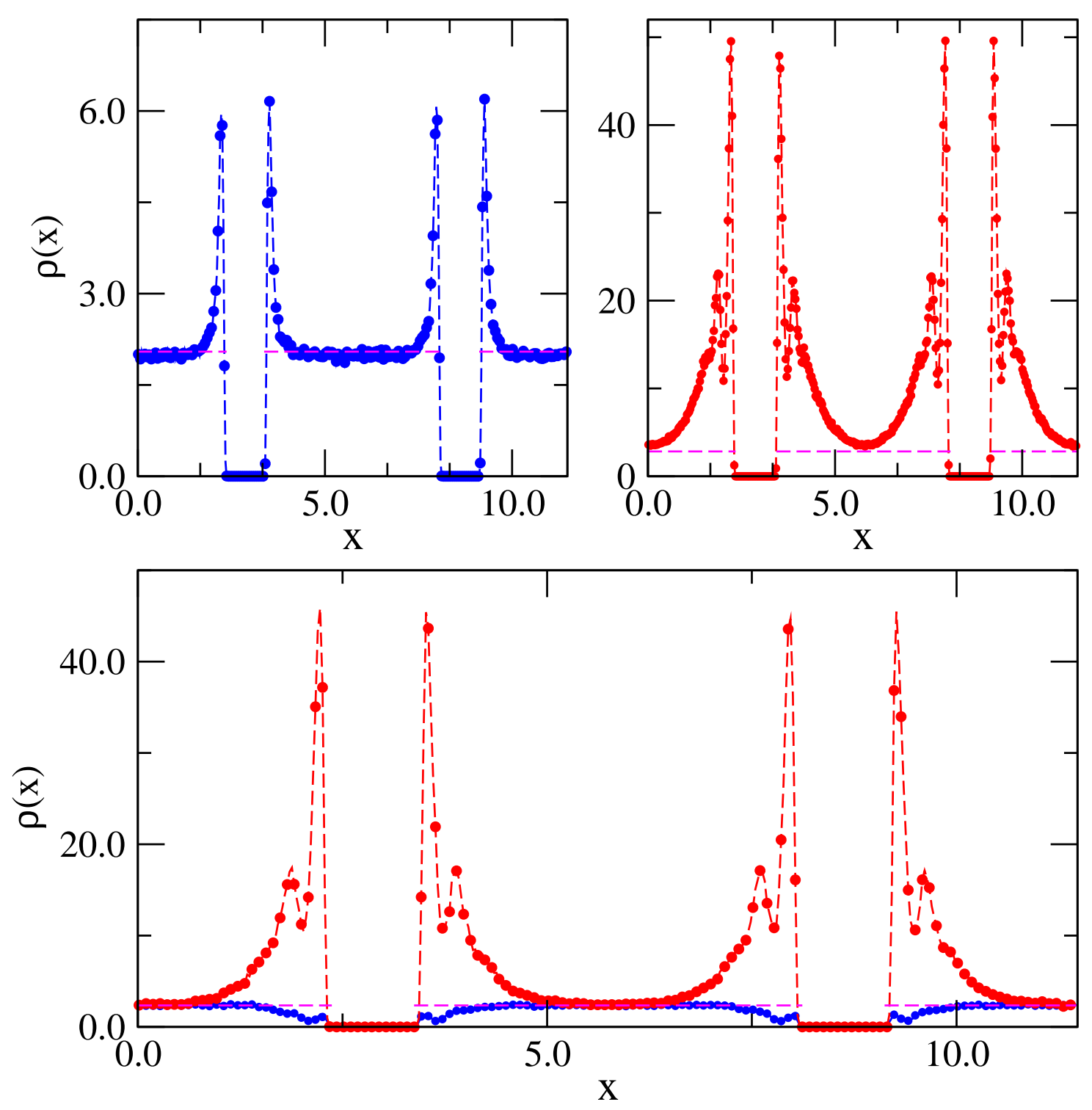

FIG. 11: 


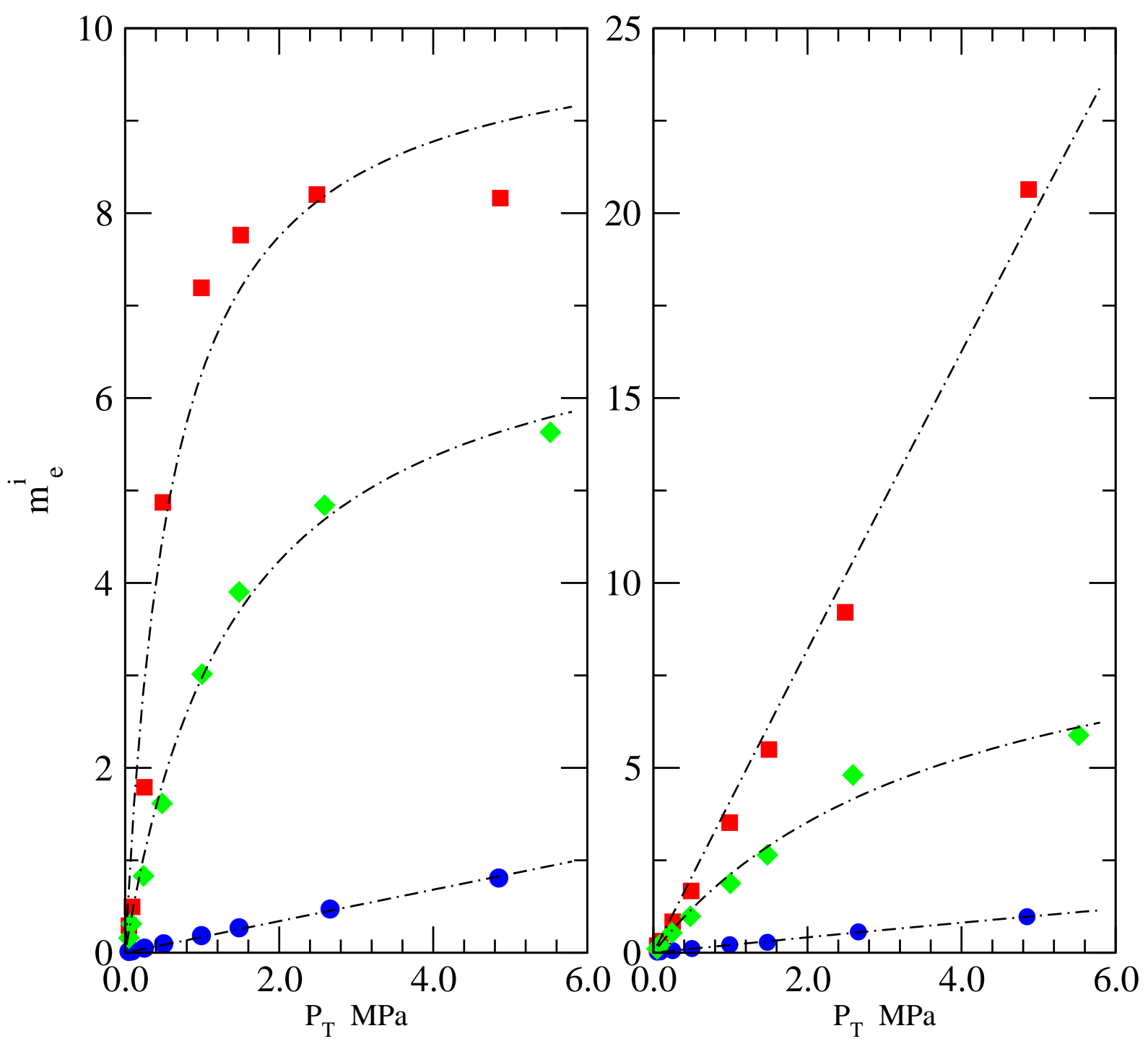

FIG. 12: 